Florida International University FIU Digital Commons

$5-29-2018$

\title{
Social Comparison in Eating Disorder Recovery: A Mixed-Methodological Approach
}

Jessica Faye Saunders

Florida International University, jsaun012@fiu.edu

DOI: $10.25148 /$ etd.FIDC006815

Follow this and additional works at: https://digitalcommons.fiu.edu/etd

Part of the Developmental Psychology Commons, and the Social Psychology Commons

\section{Recommended Citation}

Saunders, Jessica Faye, "Social Comparison in Eating Disorder Recovery: A Mixed-Methodological Approach" (2018). FIU Electronic Theses and Dissertations. 3818.

https://digitalcommons.fiu.edu/etd/3818 
FLORIDA INTERNATIONAL UNIVERSITY

Miami, Florida

\section{SOCIAL COMPARISON IN EATING DISORDER RECOVERY:}

A MIXED-METHODOLOGICAL APPROACH

A dissertation submitted in partial fulfillment of

the requirements for the degree of

DOCTOR OF PHILOSOPHY

in

PSYCHOLOGY

by

Jessica F. Saunders

2018 
To: Dean Michael R. Heithaus

College of Arts, Sciences, and Education

This dissertation, written by Jessica F. Saunders, and entitled Social Comparison in Eating Disorder Recovery: A Mixed-Methodological Approach, having been approved in respect to style and intellectual content, is referred to you for judgment.

We have read this dissertation and recommend that it be approved.

Leslie D. Frazier

Stacy L. Frazier

Maureen Kenny

Dionne P. Stephens

Asia A. Eaton, Major Professor

Date of Defense: May 29, 2018

The dissertation of Jessica F. Saunders is approved.

Dean Michael R. Heithaus

College of Arts, Sciences, and Education

Andrés G. Gil

Vice President for Research and Economic Development and Dean of the University Graduate School

Florida International University, 2018 


\section{DEDICATION}

For Becca and Enzo:

You inspired this work and made it possible 


\section{ACKNOWLEDGMENTS}

This dissertation would not have come to fruition without the assistance of multiple individuals, who together formed a team of mentorship, guidance, support, balance, and encouragement that accompanied me over the last five years. First, thank you to my mentor, Dr. Asia Eaton, for fostering an unwavering commitment to research, feminism, and social justice that has shaped not only how I view my career trajectory, but also the world. Thank you to my committee members, Dr. Dionne Stephens, Dr. Leslie Frazier, Dr. Stacy Frazier, and Dr. Maureen Kenny, for lending your insight and expertise into the development and execution of this project, and Dr. Ellen Fitzsimmons-Craft for your eating disorder research mentorship.

I would not have been able to complete this project in such a timely manner without the assistance of Sabrina Aguilar, who helped with conducting, transcribing, and coding of the PhotoVoice interviews. Thank you also to Power, Women, and Relationships (PWR) Lab undergraduate research assistants Ilemis de la Cruz, Andrew Morrison, Sheyla Tendero, and Paulina Bollat for their help with interview transcriptions. I am forever grateful to the current and former members of the PWR Lab and Department of Psychology graduate program for the ways in which you have allowed me to grow as a scholar, teacher, mentor, and friend. Specifically, thank you to Carla Abad, Renzo Barrantes, Victoria Bein, Brittany Boyd, Elsa Bravo, Iris Broce, Leo Carbajo, Sandy Gonzalez, Anna Kallschmidt, Shelly Ramos, Ana Lucia Rodriquez, Yanet Ruvalcaba, and Megan Taylor. Thank you to my family for supporting me on this journey; I know it wasn't always easy and I am forever appreciative for your patience and faith in me. This work was supported by the University Graduate School Presidential Fellowship, 
Department of Psychology Seed Funds, the Society for the Psychology of Women (APA Division 35)'s Janet Hyde Graduate Student Research Grant, and the Monte Nido \& Affiliates Sea Glass Grant. Lastly, thank you to the young women who shared their thoughts and experiences in interview, photograph, and questionnaire format. This work would have been impossible without you. May your struggles and insights remind others with disordered eating that recovery is possible. 


\section{ABSTRACT OF THE DISSERTATION \\ SOCIAL COMPARISON IN EATING DISORDER RECOVERY:}

A MIXED-METHODOLOGICAL APPROACH

by

Jessica F. Saunders

Florida International University, 2018

Miami, Florida

Professor Asia A. Eaton, Major Professor

This dissertation examines social comparison tendencies in young women during eating disorder (ED) recovery. Study one drew on a photo-elicitation method (PhotoVoice) and semi-structured interviews to examine this relation. Thirty U.S.

women, ages $18-35$, in self-defined recovery from disordered eating, used photography to capture personally-meaningful social and cultural influences on their recovery.

Participants then shared these photographs with the research team and described them in detail. Photographs and interviews were examined for social comparisons using thematic analysis, and two broad categories emerged: recovery-promoting and recovery-hindering comparisons. The presence of both upward and downward comparisons that both support and hinder recovery suggests that social comparisons during the recovery process are more nuanced than previously known.

Study two drew from these qualitative data to revise and validate an existing measure of food and body comparisons for women in ED recovery. Women from across the U.S. $(n=183)$ completed measures of body, eating, and exercise social comparison, general comparison orientation, and body dissatisfaction and disordered eating in one 
online session. After removing four items identified by theory and based on modification indices, the revised model fit the data well. Results suggest that body, eating, and exercise social comparisons continue to correlate with body dissatisfaction and disordered eating during recovery, but there are nuances in the content of the comparisons. Study three used this revised measure of social comparison to examine how the interrelations among thin ideal internalization, social comparison, and disordered eating outcomes vary throughout the disorder and recovery processes. An additional 78 women with an active ED, and 178 healthy-control women completed the abovementioned measures, along with a measure of thin-ideal internalization. Multi-group path analysis showed that the relations among these constructs change between disordered eating and recovery.

Study four drew from the same interviews explored in study one, returning to the interviews and photographs to highlight the key areas of potential change for clinicians and policymakers. Participant responses clustered into six themes: healthcare practice and access, health insurance reform, education, objectification of the female body, and mental health stigma. Direct suggestions and implications are discussed. 
TABLE OF CONTENTS

CHAPTER

PAGE

INTRODUCTION .1

STUDY I: SOCIAL COMPARISONS IN EATING DISORDER RECOVERY: USING PHOTOVOICE TO CAPTURE THE SOCIOCULTURAL INFLUENCES ON

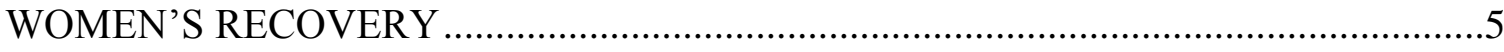

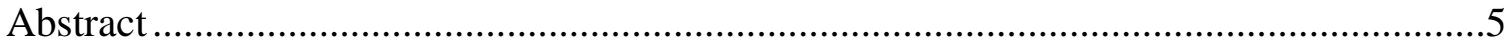

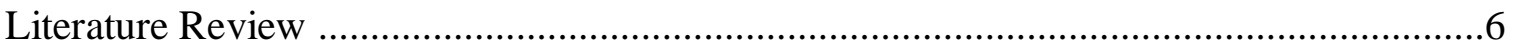

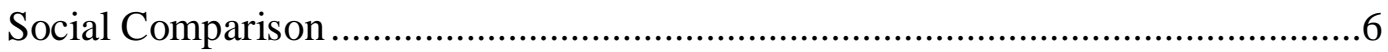

Eating Disorder Recovery …………..........................................................

Using PhotoVoice to Examine Social Comparison ...............................................

The Current Study …………………..........................................................10

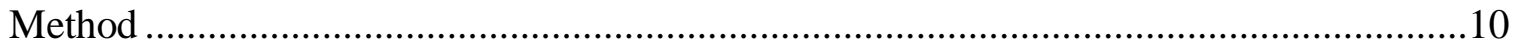

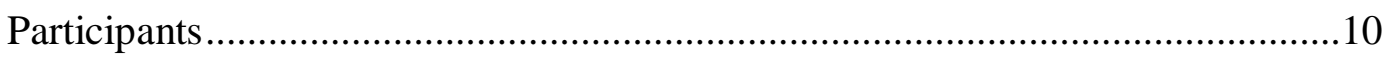

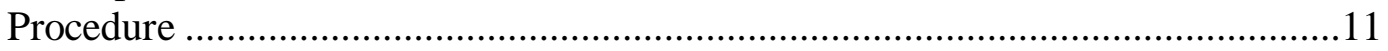

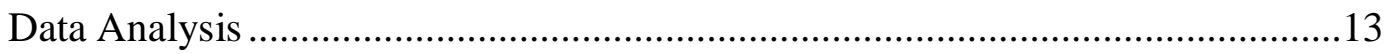

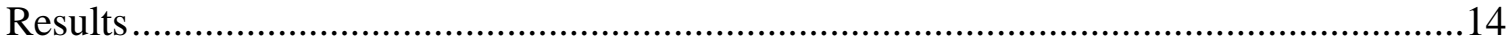

Recovery Promoting Comparisons ………………….....................................14

Recovery Hindering Comparisons .................................................................15

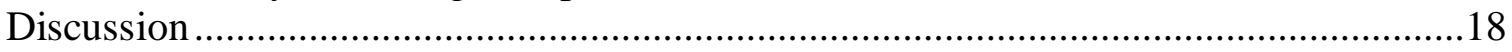

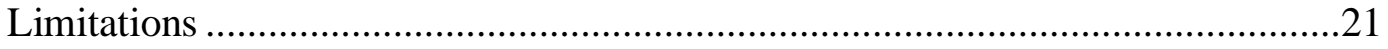

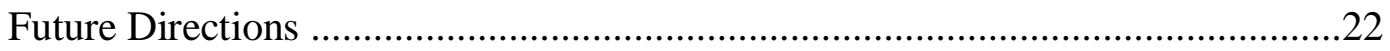

STUDY II: PSYCHOMETRIC PROPERTIES OF THE BODY, EATING, AND

EXERCISE COMPARISON ORIENTATION MEASURE (BEECOM) IN A SAMPLE

OF WOMEN IN EATING DISORDER RECOVERY …….......................................23

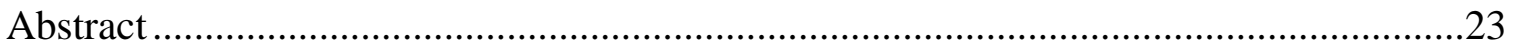

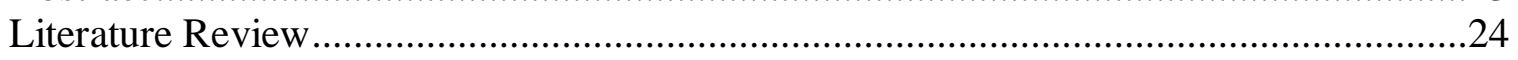

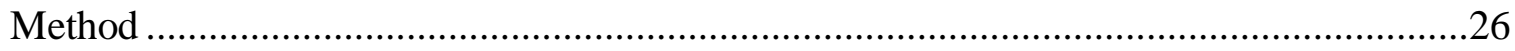

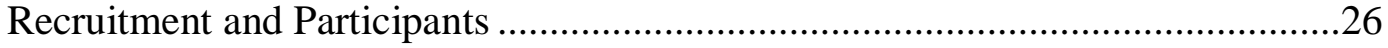

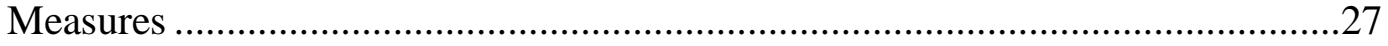

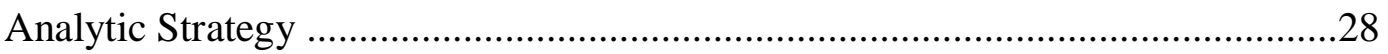

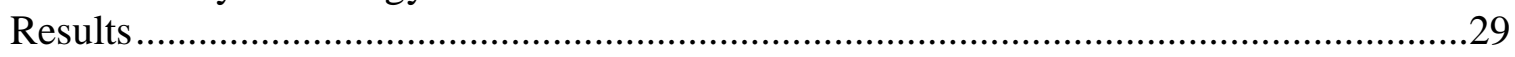

Confirmatory Factor Analysis.........................................................................29

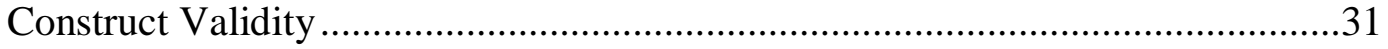

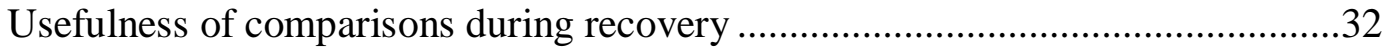

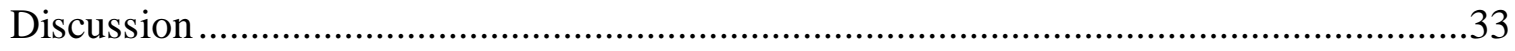


STUDY III: TO WHAT EXTENT DOES THE SOCIOCULTURAL MODEL OF DISORDERED EATING HOLD DURING EATING DISORDER (ED) RECOVERY? A TEST WITH SAMPLES OF WOMEN WITH EDS, WOMEN IN ED RECOVERY,

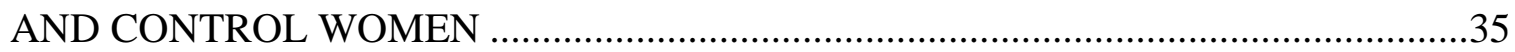

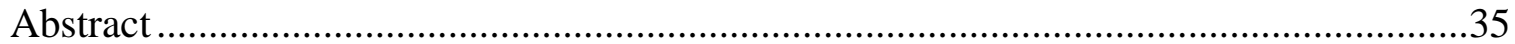

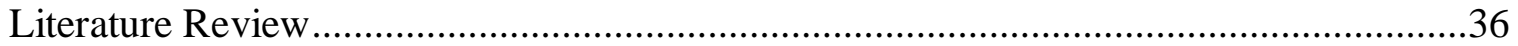

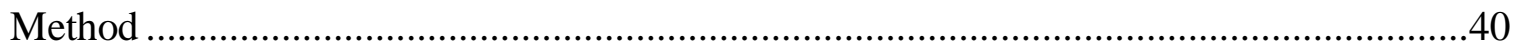

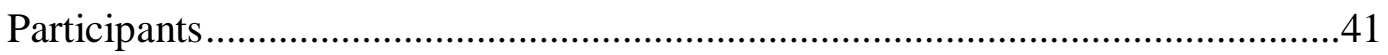

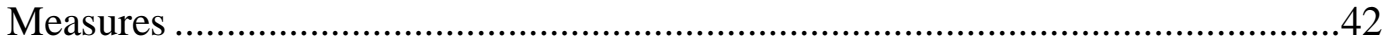

Analytic Plan and Data Screening .................................................................44

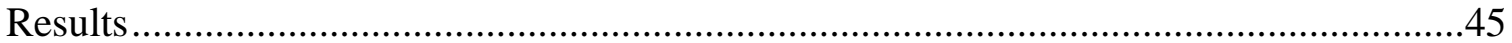

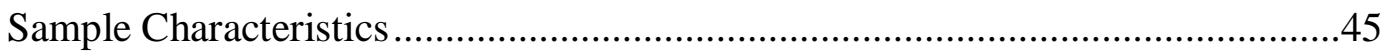

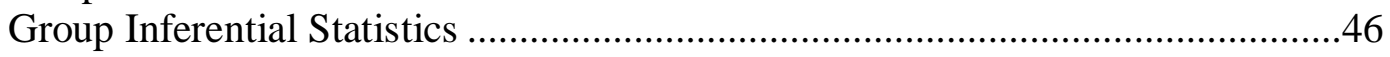

Multi-Group Path Analysis ...........................................................................4

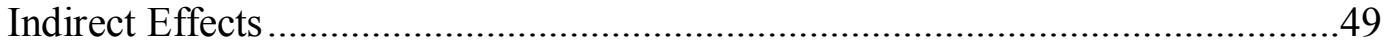

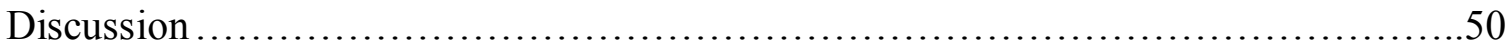

STUDY IV: DISORDERED SOCIETY: WOMEN IN EATING DISORDER RECOVERY ADVISE POLICYMAKERS ON CHANGE ...........................................53

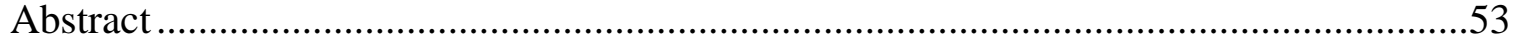

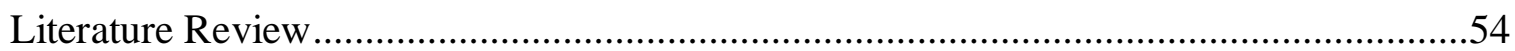

Objectified Body Consciousness and the Development of Disordered Eating .......55

PhotoVoice: A Novel Method for Research, Advocacy, and Change ...................57

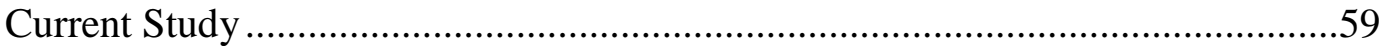

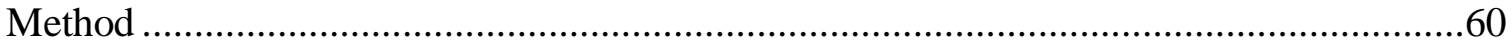

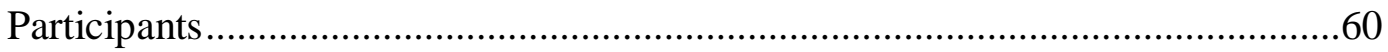

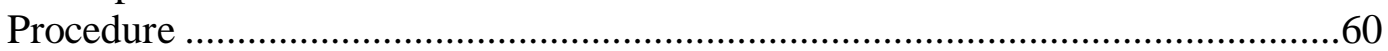

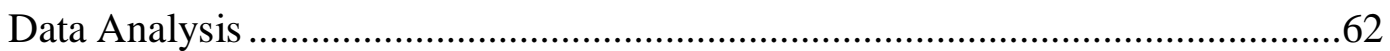

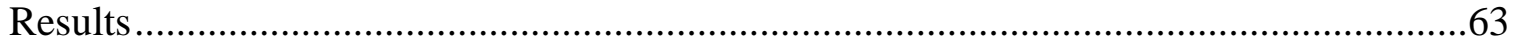

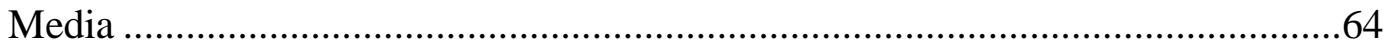

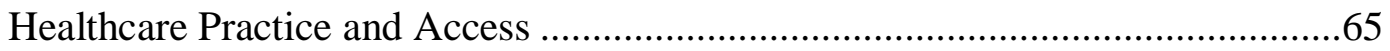

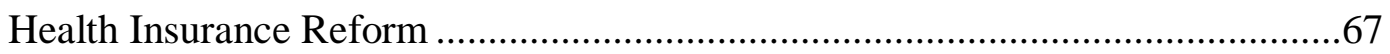

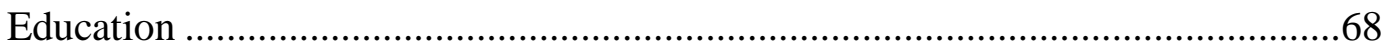

Objectification of the Female Body ……………….......................................

Mental Health Stigma .....................................................................................

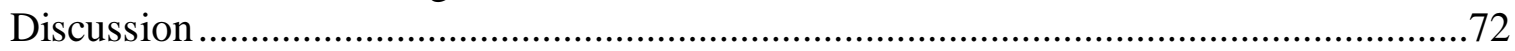

Opportunities for Reform.............................................................................

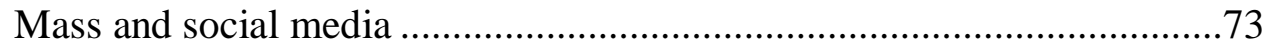

Objectification of women ...................................................................74

Healthcare practice and access.............................................................75

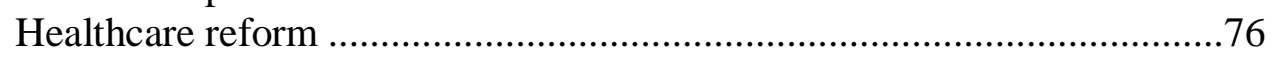

Education and stigma reduction ..........................................................76

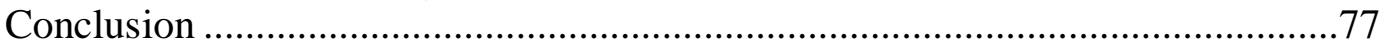

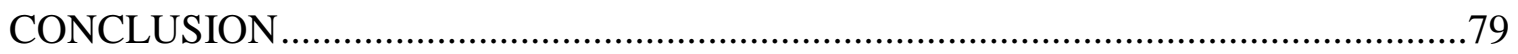


REFERENCES

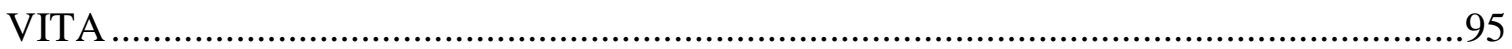




\section{LIST OF TABLES}

TABLE

PAGE

1. Items removed from the BEECOM for recovery sample ........................................30

2. Mean scores on each scale or subscale across groups. .............................................46

3. Indirect effects between thin-ideal internalization and shape and eating concerns

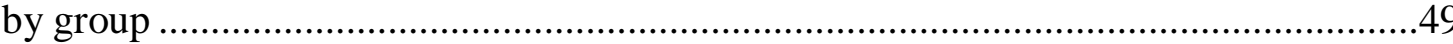

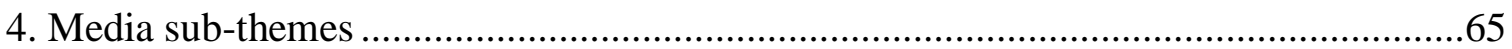

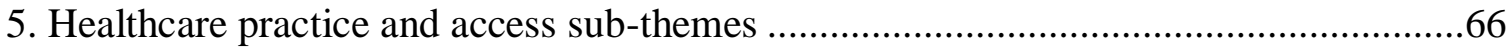

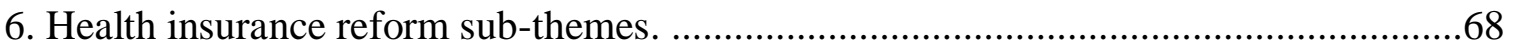

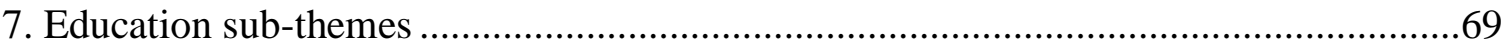

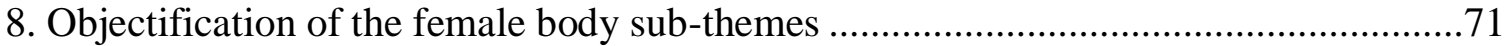




\section{LIST OF FIGURES}

$\begin{array}{ll}\text { TABLE } & \text { PAGE }\end{array}$

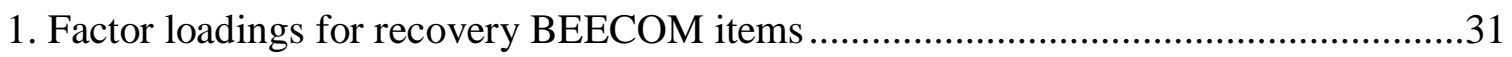

2. Hypothesized sociocultural model of disordered eating. ........................................40

3. Sociocultural model of disordered eating for healthy control group ..........................48

4. Sociocultural model of disordered eating for active ED group ................................48

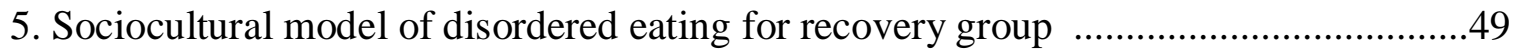




\section{INTRODUCTION}

The current project draws from social comparison and objectification theory (Festinger, 1954; Fredrickson \& Roberts, 1997; Suls \& Wheeler, 2000), within the metatheoretical framework of relational developmental systems (Overton, 2013), to better understand the individual-context relations that promote eating disorder (ED) recovery, and optimize developmental trajectories for emerging adult (Arnett, 2000) and young adult women in the United States. Relational developmental systems (RDS) theory centers on the processes that shape the interrelations between an individual and her context, processes considered to be the core of the developmental system (Lerner \& Schmid Callina, 2014). The social-cognitive processes of social comparison and selfobjectification (McKinley \& Hyde, 1996) are two of the many ways individuals attempt to regulate the relationship between themselves and their context.

In existing ED recovery research, disordered eating behaviors, and the choices one makes on a daily basis to remain in recovery, are often considered specific features of the individual (Bardone-Cone et al., 2009). For example, using body mass index as a benchmark for recovery undermines the large individual variations in ideal body weight, influenced by family history, current environment, and an individual's set-point (Lavender et al., 2015). Meanwhile, sociocultural pressures for thinness (Culbert, Racine, \& Klump, 2015) and persistent exposure to social and mass media are thought to be contextual variables (Perloff, 2014). Most theoretical and empirically tested models feature uni-directional pathways of change (Fitzsimmons-Craft et al., 2012; Stice, 2001; Tylka \& Sabik, 2010), failing to acknowledge the interplay among forces. 
From the perspective of RDS, this is an oversimplification tantamount to falsehood, and carries with it the danger of reductionistic knowledge, practice, and policy. Relational developmental systems meta-theory underscores seven epistemological categories, each of which stands in contrast to a mechanistic, Cartesian split world-view. These categories are (1) process, (2) becoming/being, (3) holism, (4) relational analysis, (5) multiple perspectives, (6) coaction, and (7) multiple forms of determination (Overton \& Lerner, 2014). Individually, these categories highlight the impossibility of splitting the individual from the culture she is embedded within, and taken together, situate the ED recovery process solidly within a developmental systems perspective. For example, prior research demonstrates that body dissatisfaction and disordered eating are how the system adjusts to the coaction between cognitive factors, such as attention bias, and an environment promoting weight loss and dieting (Saunders \& Frazier, 2017).

To integrate each of these categories, this dissertation focuses on the process of recovery, rather than the endpoint, and the never static journey towards a healthier state. The recovery process is studied holistically and relationally, by acknowledging the bidirectional loop between an individual and her environment (Kelly \& Tasca, 2016; Tiggemann, 2011). The mixed-methodological analysis used in the present dissertation aims to incorporate multiple, unique perspectives of the various forces coacting on the recovery trajectory, all of the while acknowledging that causal factors cannot be accurately identified, regardless of the research paradigm invoked.

Embodiment is a final key core concept of RDS meta-theory (Overton, 2013), and the lynchpin of the current work. According to Overton (2013), embodiment includes not just the physical appearance and function of the body, but the body as a vessel of lived 
experiences, actively immersed in sociocultural encounters. These lived experiences are captured qualitatively in the current project through the use of PhotoVoice (Wang \& Burris, 1994). As highlighted by Lerner and Tolan (2016), qualitative methodology is necessary to triangulate with quantitative measurements of the task of individuals as drivers of their own development through bidirectional individual-context relations. Studies one and four of this dissertation qualitatively examine the lived experiences of women in ED recovery, recognizing that it is impossible to extract the individual from her context. Studies two and three take a quantitative lens to these relations, refining a social comparison measure for women in ED recovery (study two), and using that measure along with measures of sociocultural influences and attitudes, body dissatisfaction, and disordered eating, to examine the same interrelations via multi-group path analysis across groups of healthy control women, women with an active ED, and women in ED recovery (study three).

Guided by RDS, the studies presented here ultimately aim to meet the overarching goals of developmental science: to capture, understand, and optimize the reciprocal changes that occur both within an individual and between the individual and her context over time (Baltes, Reese, \& Nesselroade, 1977). We seek to explain and optimize mental and physical health outcomes by examining multiple attributes of the individual within multiple levels of her ecology (Lerner, Agans, DeSouza \& Gasca, 2013), with the longterm goal of identifying critical non-clinical levers of change. The current work bridges developmental and feminist principles, with an eye to social justice and public health, to supplement existing clinical knowledge, best capture interindividual differences in change, and better meet the needs of a diverse population. Taken together, these four 
studies offer a novel lens into the recovery world of a diverse sample of young adult women, examine the unique and nuanced role of social comparison during ED recovery, highlight shifts in how the sociocultural pressures for thinness are internalized, and offer suggestions to improve the healthcare and well-being of all women, including those suffering from EDs, at a societal level. 


\title{
STUDY I: SOCIAL COMPARISONS IN EATING DISORDER RECOVERY: USING PHOTOVOICE TO CAPTURE THE SOCIOCULTURAL INFLUENCES ON
}

\section{WOMEN'S RECOVERY}

\begin{abstract}
This qualitative study draws on a photo-elicitation method ("PhotoVoice") and semi-structured interviews to examine the role of social comparison during young women's eating disorder (ED) recovery process. Thirty U.S. women, ages 18-35, in selfdefined recovery from disordered eating, used photography to capture personallymeaningful social and cultural influences on their recovery, including factors supporting and hindering their recovery process. Participants then shared these photographs with the research team and described them in detail. Photographs and interviews were examined for social comparisons using thematic analysis, and two broad categories emerged: recovery-promoting and recovery-hindering comparisons. The vast majority of comparisons related to the appearance, eating, and exercise domain, and involved friends, family, and strangers. However, the presence of both "upward" and "downward" food and body comparisons that both support and hinder recovery suggests that social comparisons during the recovery process are more nuanced than previously known.
\end{abstract}

Keywords: social comparison, eating disorder recovery, qualitative, PhotoVoice 


\section{Literature Review}

The risk factors for eating disorders (EDs) are well documented. Sociocultural pressures for thinness and the internalization of the thin ideal consistently emerge as the most robust predictors of disordered eating outcomes in young adult women (Culbert, Racine, \& Klump, 2015). According to the expanded sociocultural model of disordered eating (Fitzsimmons-Craft et al., 2014), these pressures result in heightened levels of social-cognitive processes focused on appearance, food, and weight in the form of body, food, and exercise social comparisons, with direct influence on disordered eating outcomes (Fitzsimmons-Craft, 2017). Friends, family, and the media have been identified as the most common targets of these comparisons (Keery, van den Berg, \& Thompson, 2004).

\section{Social Comparison}

Social comparison theory (Festinger, 1954; Suls \& Wheeler, 2000) posits that people will engage in comparisons with similar others as a source of self-knowledge when individuals are uncertain about their status in each domain (i.e., appearance, eating, and exercise behavior). According to the original conceptualization of social comparison theory (Festinger, 1954), individuals partake in upward comparisons (i.e., comparing themselves to a more successful individual) to motivate improvement in a given domain, and downward comparisons (i.e., comparing themselves to a less successful individual) to improve and maintain self-esteem and self-regard. The existing literature overwhelmingly supports the relationship between the tendency to engage in upward comparisons and body dissatisfaction and disordered eating (Want, 2009). More recently, frequent downward appearance related comparisons were found to be correlated with disordered 
eating for a diverse sample of women (Rancourt, Schaefer, Bosson, \& Thompson, 2015; Saunders \& Eaton, under review a). Comparing oneself to media images or unfamiliar peers seems to have similar negative short-term consequences for body dissatisfaction as comparing oneself to well-known others (Myers \& Crowther, 2007).

Lateral comparisons occur when an individual seeks accurate self-appraisal by comparing to someone similar to themselves (Festinger, 1954). Lateral body, food, and exercise-related comparisons are positively related to both concurrent and prospective disordered eating behaviors (Fitzsimmons-Craft, Ciao, \& Accurso, 2016), predicting the development of clinically significant ED profiles (Arigo, Schumacher, \& Martin, 2014). The act of engaging in frequent lateral and upward comparisons with other ED patients via social media (i.e., Facebook) is associated with greater eating pathology following treatment, compared to individuals engaging in less frequent comparisons (Saffran et al., 2016). The social-cognitive process of social comparison has been recommended as an important target of clinical interventions (Fitzsimmons-Craft et al., 2016). However, research has yet to examine how changes in social comparison tendencies promote recovery, or the directionality and differential impact of the comparisons women engage in while in the process of recovering from an ED.

\section{Eating Disorder Recovery}

Despite numerous attempts, there is still little consensus among patients, clinicians, and researchers concerning how to quantify and describe ED recovery, as the majority of studies focus solely on change in pathology (e.g., extreme dietary restriction, self-induced vomiting, and/or excessive exercise) as the outcome of interest (De Vos et al., 2017). In a qualitative study conducted by Darcy and colleagues (2010), participants 
highlighted the resumption of healthy behavioral, cognitive, and psychological patterns and indicators, such as eating without fear, restoration of weight and menses, loosening of rigid thinking patterns, and improved body image and self-esteem, as indicators of ED recovery. A 2017 meta-analysis of studies conducted with individuals in recovery highlighted self-acceptance, positive interpersonal interactions, autonomy, and personal growth as the indicators of recovery with the largest effect sizes (De Vos et al., 2017). Given the divisiveness and variability noted in the field, for the current study, we placed no restrictions on what "recovery" entailed, and allowed potential participants to selfidentify as a woman in ED recovery using on their own criterion. This decision is consistent with the use of qualitative methods, which center research on the subjective experiences of the individual (Morgan \& Smircich, 1980).

\section{Using Photovoice to Examine Social Comparison}

The existing quantitative research on social-cognitive processes, disordered eating and ED recovery, though informative, has been directed by the scientific community rather than the individuals affected. This research imposes both an additional observer's "gaze" on the research participant and limits the depth of our understanding. As highlighted by Ridge (2008), traditional, researcher-driven methods are especially liable to overlook the diverse lived experiences of both illness and recovery when studying stigmatized and isolated populations. Allowing participants to co-create the research protocol and agenda, such as self-defining recovery, is a key component to participatory action research (Morrison \& Lilford, 2001). Participatory action research (PAR) frameworks aim to gather knowledge for action along with understanding (Cornwall \& Jewkes, 1995) and place the power for directing change back in the hands of the affected 
community. Joint development of research projects and an emphasis on community action differentiate PAR frameworks from conventional social science research methods (Kemmis \& McTaggart, 2005). These frameworks, co-constructed by the research team and participants, have been employed in ED prevention settings (i.e., Piran, 2001), and are in the nascent stages as increasingly effective tools to capture the ED recovery process (LaMarre \& Rice, 2016a).

One such framework is the PhotoVoice method of PAR. The PhotoVoice method has three complimentary goals: (1) giving voice to participants' experiences and concerns, (2) engaging the community in dialogue around the key themes that emerge via photographic art and documentation, and (3) reaching the public, the larger scientific community, and policymakers (Wang \& Burris, 1994). The method involves the use of photography and accompanying narratives to explore social issues, including illness, disability, homelessness, war, and violence (Hegenraher, Rhodes, Cowan, Bardhoshi, \& Pula, 2009). PhotoVoice has been highlighted as an appropriate method for exploring sensitive topics, including body image, as participants guide the method and conversation at their pace and determined by their needs and comfort (Brunsden \& Goatcher, 2007). Furthermore, it taps into the insight and expertise of the community that might be minimized using traditional qualitative or quantitative methods. By giving voice and power back to the participants through photography, the PhotoVoice method has been linked to multiple positive psychological outcomes, including empowerment and improved self-efficacy (Foster-Fishman et al., 2005), and has been successfully invoked to change health policy, including statewide obesity prevention, improved access to handicapped parking, and limited tobacco sales (Sanon, Evans-Agnew, \& Boutain, 2014). 


\section{The Current Study}

The current study invoked the PhotoVoice method to qualitatively explore the role and type of naturalistically-occurring social comparisons, and their sociocultural correlates, in a sample of emerging and young adult women in recovery from EDs. As the pattern and function of body, food, and exercise social comparison have not yet been examined during recovery, qualitative PAR methodology is an appropriate technique to begin to explore this social-cognitive phenomenon.

\section{Participants}

\section{Method}

Women in self-identified ED recovery $(n=30)$ from both South Florida $(n=24$, $80 \%)$ and the Greater Boston area $(n=6,20 \%)$, participated in the PhotoVoice project. Participation was open to women in self-defined ED recovery between the ages of 18-35, to capture unique developmental experiences across emerging adulthood and early adulthood. Participants ranged in age from 18-35, though most were emerging adults ( $M$ $=23.37, S D=4.35)$. Emerging adulthood is the developmental period between the ages of 18 to 29 (Arnett, 2000). All but three participants were born in the United States, and all participants had resided in the United States for at least five years.

The majority of participants considered themselves White Hispanic $(n=17$, $56.67 \%)$. One-third of participants identified as White non-Hispanic $(n=10)$, two identified as Black Hispanic (6.67\%), and one as Indigenous North American (3.33\%). On average, participants reported developing their ED at age $14.5(S D=3.19)$ and had been in self-defined recovery without a substantial relapse for an average of 17 months $(S D=16.11$ months), making their average time to recovery 7.5 years. Twenty-one 
participants $(70 \%)$ had received medical or clinical treatment for their eating disorder. These data align with those previously found in ED recovery research studies, with the median time to recovery thought range from six and a half to nine years (Zerwas et al., 2013).

\section{Procedure}

Participants were recruited via paper flyers distributed on the campus of a large, Southeast, Hispanic-serving public university, social media electronic advertisements, and snowball sampling. After learning about the study requirements and providing informed consent, participants were provided with the study prompt:

"Give us insight into your recovery world. What are the social and cultural pressures and expectations in your world that support you in your recovery, and what are those that are challenging for you in your recovery? What role does comparison to others play in making recovery more challenging? What types of comparisons serve to support your recovery process? Please take photos of the things you encounter in your everyday life to answer these questions and help me to better understand your recovery process"

Participants had seven days to document their response to the prompt via as many photographs as they saw fit. All photos were taken on cellular phone cameras, although participants were offered the option of using a disposable camera provided by the research team. No guidelines on the minimum or maximum number of photos were provided to the participants. The number of photographs taken by each participant varied widely, from four to $28(M=10.13, S D=5.56)$. In-person interviews reviewing and discussing the photos were conducted between May and November 2017, one-on-one 
with the first author $(n=16)$ or the trained graduate research assistant $(n=14)$ in a location of the participant's choosing (private on-campus office space, $n=21$; coffee shop, $n=7$; park, $n=2$ ). Interviews varied in length from 30 minutes to one hour and twenty minutes $(M=49 \min 20 \mathrm{sec}, S D=13 \mathrm{~min} 12 \mathrm{sec})$.

The semi-structured interview began with the elicitation of demographic and ED background information. Participants were then invited to share the photos they selected and answered a series of questions about each one. The semi-structured interview protocol featured open-ended questions, allowing the participant to share as much or as little information she deemed relevant to her research experience, and to decline elaborating on areas of recovery she was uncomfortable sharing with the interviewer. Drawing from the SHOWeD technique (Hergenrather et al., 2009), participants (S) described what is seen in the picture, $(\mathbf{H})$ talked about what is happening, or the unseen story behind the image, $(\mathbf{O})$ related the picture to our lives, $(\mathbf{W})$ discussed why things are this way, and (D) offered ideas for what we can do about it or how they would go about changing the problem or strengthening the solution. At the end of the interview, participants had the opportunity to reflect on their recovery process, and ask any questions they had about the study procedure and goals. Interviews were audio-recorded on a hand-held Sony ICD-UX71 digital voice recorder. To preserve anonymity, participants offered a pseudonym to be used throughout the manuscript. Participants received a $\$ 25$ egift card as compensation for their time. All procedures were approved by the university's Institutional Review Board (FIU IRB-16-0473), and all participants provided informed consent for the analysis and dissemination of their photos. 


\section{Data Analysis}

Interviews were transcribed by a team of five undergraduate research assistants, and a random selection of $20 \%$ of the interviews $(n=6)$ were reviewed by an independent transcriber for accuracy. Interviews were approached using thematic analysis to extract patterns of meaning (Braun \& Clarke, 2006). The PhotoVoice method is regularly invoked to understand the data yielded from PhotoVoice projects (Han \& Oliffe, 2016). The research team took an iterative approach to coding the interviews. The first author developed an initial codebook using a series of steps customary to qualitative research to reinforce reliability and consistency between coders (Strauss \& Corbin, 1998). The codebook development was guided by social comparison theory (Festinger, 1954) and findings from prior research on the role of social comparison in disordered eating (Fitzsimmons-Craft et al., 2016; Fitzsimmons-Craft et al., 2012).

Based on feedback from the second coder, and patterns observed in the interviews, the codebook was revised. Rather than following the framework proposed by Festinger (1954), the comparison patterns for this sample of women in ED recovery fell into two distinct categories: recovery-promoting or recovery-hindering. Both upward and downward comparisons fell into each category. The first and second coders individually coded the same three randomly selected transcripts, met to discuss discrepancies among codes, and revised the codebook considering the incongruity in codes. The author then coded an additional three randomly selected transcripts and assessed reliability $(\kappa=.90)$. During the second stage of analysis, the first author reviewed each instance of comparison, and categorized it by target and overarching theme. 


\section{Results}

Across all 30 interviews, participants shared a total of 304 photographs $(M=$ $10.13, S D=5.56)$, and engaged in a total of 313 comparisons $(M=10.43, S D=6.4)$, ranging from as few as three comparisons to as many as 27 . All participants brought new photos; ten participants (33\%) also shared an older photo, to reflect back on their childhood or a particularly difficult time during their disorder. Recovery hindering comparisons occurred most frequently $(n=143)$, followed by recovery-promoting comparisons $(n=100)$. All participants engaged in at least one recovery-promoting comparison, and most participants $(63.3 \%, n=19)$, when asked directly at the end of the semi-structured interview, considered social comparison to be a helpful cognitive pattern at some point during their recovery process, under specific circumstances and motives.

\section{Recovery Promoting Comparisons}

Comparisons to ED self. All participants described at least one recovery promoting comparison focused through their chosen pictures. The most prominent recovery promoting comparison was the participants' comparison to her ED-self, with 25 participants $(83.3 \%)$ reflecting on at least one way she had changed in a positive manner relative to her former self since entering recovery, and highlighting this comparison as a reason to continue making progress. Participants often noted affirmative changes in mindset $(n=12)$, frequency, intensity, and severity of physical symptoms $(n=9)$, body image and the meaning of weight $(n=8)$, food preferences and interest $(n=7)$, cooking tendencies $(n=3)$, use of behaviors $(n=3)$, and a shift in how self-care is viewed when pregnant $(n=2)$. 
Ber (age 32) expressed satisfaction in her clear shift from her past ED

mindset, which she illustrated by sharing a selfie she had taken during her illness:

... and you can tell how sick I was by how artistic it is, too. Like I even took the time to turn it to black and white, to do the zoom in, to do the shading so it just focused on the stomach. So I guess I'm just happy that I'm not there now, in that mindset.

Comparisons to others with disordered eating. Seven participants (23.3\%) shared a picture eliciting a recovery promoting comparison to others with disordered eating. Participants approached these comparisons from multiple angles, including gratitude for the support that often accompanies interactions with others in recovery $(n=3)$, and the ability to recognize the psychological and physical benefits of recovery in others $(n=4)$. Laura (age 25), followed others on Instagram with food and mood related difficulties as a way to bolster her own recovery:

I was in a really dark place and she's just opening up and it kind of breaks that bubble again of she's not perfect, no one is perfect even though she looks like this, she's going through a lot of hard things and... people replying to her in a very positive way made me want to share my story.

Comparisons to healthy others. Nearly half $(n=14)$ of participants noted the benefit of comparing to healthy female others, including friends, coworkers, and female family members. Seeing others eating freely normalized the experience for multiple participants $(n=5)$, and led them to continue the recovery journey. Participants also commented on their persistent hope to one day achieve the freedom with food and exercise perceived in others $(n=8)$. 
Comparisons to healthy others into the body image domain, with comparisons

to others without EDs across a spectrum of body sizes and types $(n=11)$

supporting the recovery process.

Her whole thing is like, "if I can do it, you can do it" and she's blown up like she's all over like, social media and stuff like that so it was just like I keep trying to find people like that like, that were kind of like ...my inspiration for things....people like that, I guess, inspire me forward. (Lillian, age 25)

\section{Recovery Hindering Comparisons}

Comparisons to ED self. Nearly $75 \%(n=22)$ of participants noted the ways in which comparing their current body $(n=13)$, clothing $(n=6)$, and other ED patients $(n=3)$ to their body during their ED made recovery more challenging. The appearance of comparisons to the ED self in both categories illustrates that the same target, and the same features of a target, can serve as both a source of inspiration for recovery or regression to illness. In other words, the old ED self appears as both an "upward" target, inspiring one to pursue health, or an "upward" target inspiring one to pursue illness, depending on the current mindset and motivation of the individual. These comparisons were shared with the interviewer through pictures of mirrors, old selfies, and clothes.

I can't look at my own pictures. I can't go back and look at them. It sets things off. It hurts. I really am not kidding when I tell you I was the happiest with my body when I was (inaudible). And, like, looking back at it, even in this picture I thought I was larger... because I was, I was larger than I used to be. But, I would die to have that body again. Not, like, literally die. But, you know... (Steph, age 31)

Comparisons to models and actresses. Body comparisons extended beyond the self to actresses and models, or women seen in the general media and across social 
media platforms, with half of the participants $(n=15)$ sharing a photo that elicited at least one comparison to Instagram personalities $(n=8)$, women in television and film $(n=5)$, lingerie models $(n=2)$, fitspiration images $(n=2)$, athletes $(n=2)$, print media $(n=2)$, and Barbie $(n=1)$.

...there's like some ad I saw in a movie when I was a kid, and it talked about a guy getting a 120lb Christmas gift, and then showed this leggy blonde woman and I was like 11 and I weighed more than 120lbs and I was like, wait, is that what women are supposed to weigh? ... So like, all of these numbers I hear, if I'm not these numbers, then I'm wrong. (Jane, age 30)

Comparisons to strangers. Nearly one-third of all participants $(n=9)$ discussed the ways in which comparisons with strangers' smaller bodies $(n=7)$, eating patterns $(n=2)$, athletic abilities, particularly practicing yoga $(n=2)$, or weight loss $(n=1)$, negatively impacted the recovery experience.

I will sit through dinner and I will look at people and I'll randomly say "Why she's so pretty?" and then my boyfriend's like "What?" and I'm like "You didn't see her walk by?" and it's like he didn't even notice because I'm the one that's looking at everybody cause I'm trying to find something to compare myself with all the time. (Lola, age 20)

Comparisons to peers. Half of the participants $(n=15)$ compared their body, food, and exercise patterns to those of friends in face-to-face interactions $(n=9)$, friends on social media $(n=3)$, boyfriends $(n=3)$, and co-workers $(n=3)$. Participants compared on multiple attributes, including appearance, shape, size, intake, and distance run.

And then I was like "damn, I'm skinnier than all these girls, but I still hate how I look. I still don't feel as good as them."....and, and I actually took a laxative, I purged, the day before. (Ana, age 20) 
Comparisons to older female relatives. Three participants (10\%) noted the

detrimental nature of comparisons to older, female relatives.

My aunt was there, my aunt loves to eat and she's really obese. Not like extremely obese but she's there. So seeing her gives me anxiety too because like oh my god I can get like that. (Nina, age 21)

Comparisons to societal and medical ideals regarding food and weight. Five participants (16.67\%) discussed the ways in which comparisons to society or the medical community's food $(n=4)$ and weight $(n=3)$ ideals makes the recovery process significantly harder.

Sometimes I want to throw it out but I'm still trying to lose weight because I'm not comfortable at the weight I'm at because like I still will Google like oh "Is my number like um normal for my age and my height?" And it's not. And that makes me upset so I still wanna lose weight. (Riley, age 21)

\section{Discussion}

In the current study, we described the most common forms of social comparison held by a diverse sample of emerging and young adult women in ED recovery. Contrary to prior quantitative work (i.e., Fitzsimmons-Craft, 2017; Lin \& Soby, 2016; Saunders \& Eaton, under review a) demonstrating that all body, food, and exercise comparisons are detrimental to the recovery experience, these comparisons, rather than falling along the upward-lateral-downward spectrum, reduced into two categories: recovery promoting or recovery hindering. Notably, both upward and downward comparisons appeared with regularity in the two categories, suggesting that the benefits and impediments of body, food, and exercise social comparison are incredibly nuanced. 
Body, food, and exercise comparisons occurred with great frequency. The majority of these comparisons were recovery hindering, and featured comparisons to the ED self, models and actresses, and peers, either in face-to-face or online interactions. This finding is expected, given prior findings emphasizing the detrimental effect of any body, food, or exercise comparison on disordered eating outcomes, including those to peers in recovery (Saffran et al., 2016). The common targets align with those predicted by the Triparte Influence Model (Keery, van den Berg, \& Thompson, 2004), with the ED "self" replacing family as the third mode of influence. Given the egosyntonic nature of EDs, particularly anorexia nervosa (Gregertsen, Mandy, \& Serpell, 2017), the continued comparison to the self is unsurprising. Most participants shared an image related to their appearance or clothing size when ill, and mentioned a longing to return to a similar shape or size.

Notably, the vast majority of participants also underscored positive comparisons to their ED self, indicating that although these comparisons can serve to hinder the recovery process, there were physical and behavioral changes that outweighed returning to a "sick" body. Some participants expressed a desire to return to their pre-recovery bodies, but did not express a similar desire to return to the severe psychological and physical symptoms associated with their disorders. Others viewed all components of the ED, including a potentially different-sized body, as something they never wanted again. These findings are in line with the often ambivalent nature of the recovery process (Darcy et al., 2010), and prior research highlighting the shift most women in recovery experience from dichotomous to holistic thinking about the self when they fully embrace the benefits of recovery (Jenkins \& Ogden, 2012). 
Following comparisons to the ED self, the next common targets, with comparisons falling into both categories, were individuals on social media, most notably Instagram. Recovery hindering appearance comparisons to peers and celebrities were mentioned with great frequency. Recent research has highlighted the negative effects of attractive celebrity and peer images (Brown \& Tiggemann, 2016) and fitspiration images (Holland \& Tiggemann, 2017) on Instagram in women without a clinical ED diagnosis. It follows that women in recovery would find these images difficult to view. As an antidote to viewing these triggering images, a handful of participants recommended seeking out social media content promoting body positivity and open discourse around body image.

Several participants shared images of healthy or clean eating, noting that when they could not achieve that ideal, they felt poorly about themselves and the recovery process. Participants in LaMarre and Rice's (2016b) study expressed similar frustrations, as recovery prescriptions have been situated within a sociocultural context dichotomizing food, health, and bodies into good and bad, or healthy and unhealthy that oftentimes run counter to the realities of the recovery process (LaMarre \& Rice, 2016b). The relativity of the term healthy became evident in the current study, as participants noted both the benefits and drawbacks of comparing their eating patterns to healthy peers. These comparisons served as assurance that eating a particular food would not be harmful and as motivation to achieve a greater freedom with food, and also left participants grappling with what it meant to eat healthfully. Participants also expressed discomfort and frustration when comparing their intake and exercise to that shared by others on social media, as it activated ED thoughts. This finding aligns with prior research relating calorie and fitness tracking to increases in ED symptomology (Simpson \& Mazzeo, 2017), and 
highlights both the importance of eliminating this behavior during ED recovery and the subjectivity of health in our modern culture.

\section{Limitations}

Despite providing a foundational understanding of the type and function of social comparisons related to body, food, and exercise, the current study comes with limitations. The sample consisted of women in self-defined recovery. While that methodological decision is consistent with the literature (De Vos et al., 2017), particularly findings that patient reported outcomes are often most comprehensive (Winkler et al., 2017), our sample demonstrated much heterogeneity in terms of recovery stability and progress. Narrower inclusion criteria regarding behavior use, psychological status, and time in remission would elucidate how comparison tendencies might differ at different stages of recovery (see Bardone-Cone et al., 2009).

The current sample was also transdiagnostic, and while most EDs demonstrate diagnostic changes over time (Allen, Byrne, Oddy, \& Crosby, 2013), it precludes investigation of the possible differences and likely similarities in the type and function of social comparison among diagnoses. Lastly, ED recovery is a vulnerable and personal process, and the individuals willing to share a part of their journey with the scientific community share a self-selection bias (Braver \& Bay, 1992). Although one of the two interviewers also self-identifies as a young woman in ED recovery, that information was withheld from participants until the interview was complete. As such, participants may have viewed the interviewer more as an expert than as a fellow member of the recovery community. The participants may have selected pictures and provided answers to the 
semi-structured interview that they viewed as socially desirable, and omitted relevant comparisons (Spector, 2004).

\section{Future Directions}

Using the PhotoVoice method, the current study sheds light on the role of social comparison for women in ED recovery. As these results are descriptive in nature and derived from the recovery process of two communities of emerging and young adult women, future research needs to examine the role of social comparison in a more generalizable manner. Given our finding that directionality of the comparison is less salient and impactful than the motive and function, a quantitative examination of social comparison tendencies in this unique population should not only examine the type of comparisons, but also their differential impact and motive. Existing quantitative measures (e.g. Fitzsimmons-Craft et al., 2012; O’Brien et al., 2009) would need to be validated for a population of women in ED recovery, and adapted to account for the distinctive uses of comparison during the recovery process. 
STUDY II:

PSYCHOMETRIC PROPERTIES OF THE BODY, EATING, AND EXERCISE

COMPARISON ORIENTATION MEASURE (BEECOM) IN A SAMPLE OF WOMEN

IN EATING DISORDER RECOVERY

\begin{abstract}
Body, eating, and exercise social comparisons are strongly associated with body dissatisfaction and disordered eating. However, no study to date has quantitatively examined these constructs during eating disorder (ED) recovery. The current study aimed to do so, by validating an existing measure of body, eating, and exercise social comparisons that had not been previously administered to the ED recovery population. The sample consisted of women in self-defined ED recovery, between the ages of 18-35 $(N=183)$ who completed measures of body, eating, and exercise social comparison, general comparison orientation, body dissatisfaction, and disordered eating in one online session. The eating pathology scores were used as an additional metric of ED recovery. The initial model fit the data poorly. After removing four items by prior research and theory, the revised model fit the data well, as indicated by a significant change in the ChiSquare test of model fit. Results suggest that body, eating, and exercise social comparisons continue to correlate with body dissatisfaction and disordered eating during recovery, but there are nuances in the content of the comparisons.

Keywords: eating disorder recovery, social comparison, body dissatisfaction, disordered eating
\end{abstract}




\section{Literature Review}

Eating disorders (EDs) are serious mental illnesses associated with high morbidity and mortality, clinical impairment, and comorbid psychopathology (Klump, Bulik, Kaye, Treasure, \& Tyson, 2009). Mortality from anorexia nervosa (AN) is the highest of all mental disorders (Keel \& Brown, 2010). Although not all women fully recover and the process can be quite long, most women recover from clinical EDs over time (Eddy et al., 2017). Duration of illness is one of the strongest predictors of mortality, with longer durations associated with higher standardized mortality ratios (Franko et al., 2013). Thus, identification of modifiable factors that are cost-effective to target to accelerate and solidify ED recovery trajectories is critical. Social comparison may be one such modifiable, social-cognitive factor.

Social comparison theory (Festinger, 1954) posits that individuals compare to similar others to ascertain where one stands in a given domain, either to motivate improvement and change or preserve self-esteem. The tendency to engage in appearance related comparisons has been shown to be strongly associated with ED symptoms (Rancourt, Schaefer, Bosson, \& Thompson, 2015) and predicts the development of eating pathology within one college semester (Arigo, Schumacher, \& Martin, 2014). Furthermore, appearance-related social comparison behaviors are higher in women displaying clinical ED symptomology than in women with sub-clinical or non-disordered eating patterns (Leahey, Crowther, \& Ciesla, 2011).

While the majority of ED related social comparison studies have focused solely on appearance-related comparisons, more recent research highlights how body, eating, and exercise social comparisons are also potential triggers for disordered eating 
cognitions and behaviors (Fitzsimmons-Craft, 2017; Fitzsimmons-Craft et al., 2016). When included in the expanded sociocultural model of disordered eating (FitzsimmonsCraft et al., 2014, 2012), these comparisons mediate the relationship between thin idealization and body dissatisfaction for non-clinical female samples. Body-, eating-, and exercise-related social comparisons have also been examined qualitatively during behavioral remission, to better understand the function these comparisons serve during recovery (Saunders \& Eaton, under review).

However, no study to date quantitatively examines how body, eating, and exercise social comparison operates during ED recovery/ Furthermore, no existing social comparison measure has been psychometrically evaluated for use with this population. The current study aimed to fill this gap in the literature by evaluating the psychometric properties of an existing body, eating, and exercise comparison measure (BEECOM; Fitzsimmons-Craft, Bardone-Cone, \& Harney, 2012) and the relationship between these comparisons, ED symptomology, and general social comparison tendencies in a sample of women in ED recovery. Participants were previously diagnosed with a clinical ED and in behavioral remission and psychological recovery. We hypothesized that the final version of the BEECOM for use in individuals in recovery from an ED would be revised relative to the original version, given that some of the items, particularly those involving eating comparisons, may no longer be as relevant for capturing these women's experiences. 


\section{Method}

\section{Recruitment and Participants}

Participants were women $(n=183)$ in ED recovery recruited via the social networking sites Facebook and Instagram, primarily through recovery- and treatmentfocused groups, $(n=161)$ or a university undergraduate study pool $(n=22)$. The recruitment advertisement invited women who currently or previously had struggled with food-related concerns to partake. Participants from the community did not receive compensation; participants from the university undergraduate study pool received course extra credit in exchange for their time. All procedures were approved by the university's Institutional Review Board, and all participants provided informed consent.

We allowed participants to self-define recovery as there is little consensus among clinicians and researchers concerning the appropriate recovery criterion (de Vos et al., 2017), and patients often have similar criteria for recovery to those broadly considered by the clinical and scientific communities (Darcy et al., 2010). Given the high rates of diagnostic crossover in the ED population (Allen, Byrne, Oddy, \& Crosby, 2013), and the common core characteristics across all diagnoses (Culbert, Racine, \& Klump, 2015) our sample was transdiagnostic. The self-defined ED recovery criteria was strengthened by the exclusion of participants whose EDE-Q global scores exceeded two standard deviations of community norms, or those who reported engaging in disordered eating behaviors (purging, bingeing, laxative use, or compensatory exercise) and resulted in the exclusion of 47 participants. The final sample size for the subsequent analyses was 136 . The sample consisted of women between the ages of $18-35\left(\mathrm{M}_{\mathrm{age}}=26.2, S D=5.2\right)$, and was predominantly non-Hispanic White (71.4\%), followed by Hispanic White $(24.2 \%)$, 
Multiracial (3.3\%), and Native American (1.1\%). Participant education, used as a proxy for socioeconomic status, ranged from less than High School (2.2\%) to Doctorate (4.4\%), with the median \& most frequent response being Bachelor's Degree (38.5\%).

\section{Measures}

Body, Eating, and Exercise Social Comparisons. The BEECOM (Fitzsimmons-Craft et al., 2012) was used to assess body-, eating-, and exercise-related social comparisons. The existing scale consists of six items for each comparison domain. Items are rated on a 7point scale ranging from never (1) to always (7). The scale's authors report high internal consistency for the full scale ( $\alpha=.96$; Fitzsimmons-Craft et al., 2012). The internal consistency in the current sample matched that of the initial scale validation $(\alpha=.96)$. In a sample of non-clinical college women, scores on this measure were positively correlated to disordered eating behaviors (Fitzsimmons-Craft et al., 2014). In the current study, participants were also asked to indicate if "this type of comparison is helpful in [my] recovery process (promotes healing and staying in recovery" for each of the 18 comparison items, with the response options of "yes/helpful," "unsure/neutral," or "no/unhelpful."

General Social Comparison Tendencies. The Iowa-Netherlands Comparison Orientation Measure (INCOM; Gibbons \& Buunk, 1999), was used to assess general social comparison tendencies. The scale consists of 11 items (two of which are reverse coded). Items are rated on a 5-point scale, ranging from I disagree strongly (1) to I agree strongly (5). The internal consistency for the current sample was adequate $(\alpha=.78)$. Eating Disorder Symptomology and Recovery. The Eating Disorder Examination Questionnaire (EDE-Q; Fairburn \& Beglin, 2008) was used to quantify ED 
symptomatology and consists of 20 items assessing frequency of thoughts and behaviors as rated on a 7-point scale, ranging from no days (0) to everyday (6) over the course of the past 28 days, and eight questions assessing the degree to which an individual experienced certain disordered cognitions about food body, and weight, rated on a 7-point scale ranging from not at all (0) to markedly (6) . The EDE-Q consists of four subscales: (1) dietary restraint; (2) eating concern; (3) weight concern; and (4) shape concern, which are averaged to compute the global score. Global scores on the EDE-Q demonstrate strong internal consistency $(\alpha=.90$; Peterson et al., 2007). For the current sample, the internal consistency was high $(\alpha=.95)$.

\section{Analytic Strategy}

All data were missing completely at random (MCAR, Little's MCAR $\chi^{2}(397)=$ 428.984, $p<.129$ ) and missing values were imputed using the Expectation Maximization (EM) algorithm in SPSS 20.0 (2011). We first performed a confirmatory factor analysis (CFA) to assess whether the published model for the BEECOM provided an adequate fit to the data, and revised the model based on theoretically driven modification indices. Scores on the revised BEECOM were then correlated with measures of disordered eating (EDE-Q, Fairburn \& Beglin, 2008) and general comparison orientation (INCOM, Gibbons \& Buunk, 1999). We probed the relationship between the perceived usefulness of each comparison item with the degree to which the comparison is engaged in, with perceived usefulness (Yes, Unsure, No) as the independent variable and item score as the dependent variable. Last, we examined the relationship between the perceived usefulness of each comparison item with eating 
disorder symptomology, controlling for frequency of comparison, in analyses of covariance (ANCOVAs).

\section{Results}

The vast majority of the sample (93\%) had received psychiatric care for their disorder. This finding is in contrast to prior work indicating that nearly $80 \%$ of individuals with disordered eating do not receive care (Kazdin, Fitzsimmons-Craft, \& Wifley, 2017), and likely speaks to the specific recruitment strategy used. Sixty percent of the sample self-reported being primarily in recovery from anorexia nervosa, $17 \%$ from bulimia nervosa, $12 \%$ from binge eating disorder, and $11 \%$ from otherwise specified feeding and eating disorder. The vast majority $(76 \%)$ of participants reported being in a weight range deemed appropriate for their body by clinicians, and $12.5 \%$ of participants reported experiencing a recent (within three months) recovery-promoting change in weight. Nearly a quarter of the sample (23\%) had also used exercise for compensatory means during their disorder.

\section{Confirmatory Factor Analysis}

The data were analyzed using MPlus 7.0 (Muthén \& Muthén, 2012) and, as hypothesized, fit the published model (Fitzsimmons-Craft, Bardone-Cone, \& Harney, 2012) poorly: $\chi^{2}(122)=378.482, p<.001, \mathrm{RMSEA}=.122,90 \%$ CI $[.108, .136], \mathrm{CFI}=$ $.898, \mathrm{TLI}=.87, \mathrm{SRMR}=.055$. Based on modification indices above the threshold (Kline, 2011) suggesting cross-loading and theory, four items that may lead to disordered eating, but then transform in meaning and importance during the recovery process, were

removed (see Table 1) and the model fit improved: $\chi^{2}(64)=378.482, p<.001$, RMSEA $=$ $.08,90 \%$ CI $[.067, .10], \mathrm{CFI}=.96, \mathrm{TLI}=.94, \mathrm{SRMR}=.038$, which represented a 
significant improvement relative to the original model based on a chi-square difference test, $\Delta \boldsymbol{\chi}^{2}(58)=244.22, p<.001$.

\section{Item}

1. I look at the amount of food my peers leave on their plate in comparison to me when they are finished eating.

8. I am quick to notice how healthy (or unhealthy) my peers' food choices are compared to my own food choices.

16. I pay attention to how much junk food my peers eat compared to me

17. I pay attention to whether or not I am as toned as my peers

\section{Factor Loading $\quad$ Mod Index}

0.68

Load onto Body, 12.151

0.7

Load on to

Exercise, 8.6

\section{Table 1. Items removed from the BEECOM for recovery sample}

Though the chi-square fit statistic remained significant, this test is not considered a robust predictor of model fit (Browne \& Cudeck, 1993). Three of these four items were eating-related comparisons, which is notable given the specifics of the current sample, and may underscore a shift in thinking about food that occurs during the recovery process, such that these behaviors would no longer be engaged in. As depicted in Figure 1, all items loaded significantly onto their respective factor. As with the original BEECOM, the three factors were highly correlated, suggesting a higher order comparison tendency encompassing the body, eating, exercise social comparisons among women in recovery from clinically significant disordered eating. 


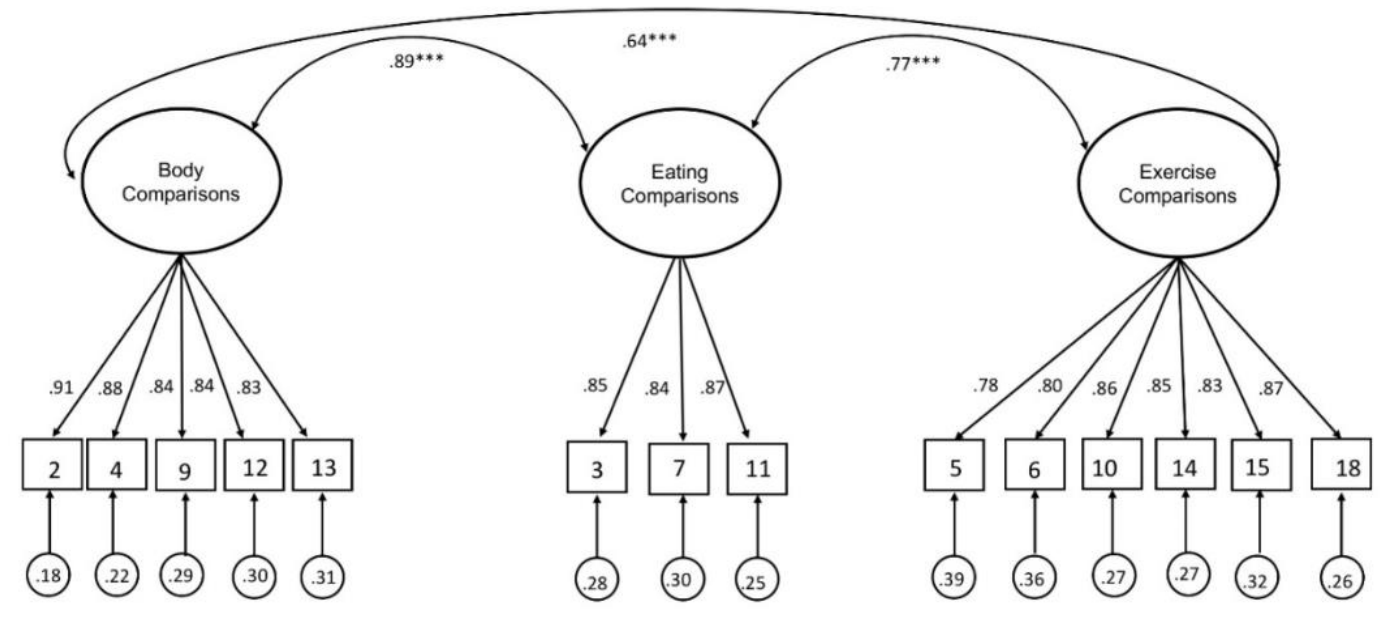

Figure 1. Factor loadings for recovery BEECOM items

\section{Construct validity}

Scores on the revised BEECOM were subsequently correlated with scores on the EDE-Q (Fairburn \& Beglin, 2008) and INCOM (Gibbons \& Buunk, 1999) to assess construct validity. Total BEECOM scores $(M=66.22, S D=16.15)$ were significantly and positively correlated with both global disordered eating tendencies $\left(M_{E D E-Q}=2.1, S D=\right.$ $1.1, r=.51, p<.001)$ and general social comparison orientation $($ MINCOM $=40.7, S D=6.46$, $r=.26, p<.002)$. When examined by subscale, body related comparisons $(M=27.9, S D=$ 6.1) were positively correlated with eating ( $M$ eatingconcern $=1.54, \mathrm{SD}=1.02, r=.37, \mathrm{p}$ $<.001)$, shape $\left(M_{\text {shape }}=2.62, S D=1.22, r=.47, p<.001\right)$, and weight concern $\left(M_{\text {weight }}\right.$ $=2.5, S D=1.1, r=.46, p<.001)$ and restraint $\left(M_{\text {restraint }}=2.02, S D=1.35, r=.23\right.$, $p<.009)$. Eating comparisons $(M=23.58, S D=7.98)$ were also significantly correlated with each EDE-Q subscale at $p<.001$ (restraint $r=.303$, eating concern $r=.43$, shape concern $r=.51$, weight concern $r=.49)$, as were exercise comparisons $(M=14.66, S D=$ 3.81), with $r$ 's ranging from .24 (restraint) to .42 (shape concern). Notably, the global 
EDE-Q and INCOM scores were also significantly and positively correlated $(r=.22$, $p<.008)$, suggesting that general comparison tendencies are also common common in women recovering from clinical EDs.

\section{Usefulness of comparisons during recovery}

To better understand social comparison processes in recovery, participants were asked whether they viewed each comparison target as helpful to their recovery trajectory. A small minority of participants found some types of comparisons helpful (2.2\% to $8.1 \%$ across items). For one of the remaining 14 items (Item 3: During meals, I compare what I am eating to what others are eating), the amount individuals engaged in comparisons differed based on their perception of its helpfulness, $F(2,182)=5.205, p<.006$. To further probe this finding and determine if perceived helpfulness related to lower ED symptomology, we conducted an ANCOVA, with perceived helpfulness of the comparison (yes, unsure, no) as the independent variable and EDE-Q scores as the dependent variable, covarying the level of comparison, $F(2,181)=4.245, p<.016$. Results demonstrated that if a participant perceived this particular comparison to be helpful, she was more likely to have a lower global EDE-Q score (1.721 for Yes compared to 2.373 for Neutral and 2.721 for $N o$ ). These participants were using this one comparison, likely in a variety of settings, to support and bolster their recovery. For all of the other items, perceived helpfulness did not relate to either the frequency the comparison was engaged in $\left(p^{\natural} \mathrm{s}>.05\right)$ or global EDE-Q scores, controlling for frequency of the comparison $\left(p^{6} \mathrm{~s}>.05\right)$. 


\section{Discussion}

The current study provides the foundation for exploration of the role body, eating, and exercise comparisons play during the ED recovery process by assessing the psychometric properties of the only existing, validated measure of these comparisons (BEECOM;

Fitzsimmons-Craft et al., 2012) in a sample of women in ED recovery. Items that may lead to disordered eating, but then transform in meaning and importance during the recovery process, were eliminated from the scale for this sample. The four removed items mention constructs that become less salient during the recovery process, such as looking at the amount of food a peer leaves on her plate when finished eating, the amount of junk or health food one consumes in relation to her peers, and the degree to which one's body displays muscle definition. Individuals in ED recovery are often prescribed a meal plan to follow to normalize eating patterns (Mittnach \& Bulik, 2015), and therefore become less focused on the amount of food left behind by others in relation to themselves. Furthermore, prior research has highlighted the ways in which ED recovery is perceived as counter-cultural (LaMarre \& Rice, 2016), with what is considered healthy or junk food no longer polarized into these two categories. Prior research has demonstrated how, in recovery, comparing the healthfulness of one's food choices to someone else's often leads to confusion over what constitutes health, as a healthy option for someone without a history of an ED may differ from that of someone in recovery (Saunders \& Eaton, under review $b)$.

The current study, though informative and aligned with predictions concerning the differential role of body, eating, and exercise comparisons during recovery, should be replicated with other recovery samples, including those who would be classified as 
recovered by more stringent definitions (i.e. Bardone-Cone et al., 2009) than the one used here. Additionally, an exploration of body, eating, and exercise social comparisons across diagnostic groups may clarify if these comparisons differ based on primary symptomology. 


\title{
STUDY III. TO WHAT EXTENT DOES THE SOCIOCULTURAL MODEL OF DISORDERED EATING HOLD DURING EATING DISORDER (ED) RECOVERY? A TEST WITH SAMPLES OF WOMEN WITH EDS, WOMEN IN ED RECOVERY, AND CONTROL WOMEN
}

\author{
Abstract \\ The sociocultural model of disordered eating, which proposes links between thin- \\ ideal internalization, social comparison, and disordered eating outcomes, is well \\ established among individuals with eating disorders (EDs) and healthy controls. \\ However, the relationship between these social-cognitive constructs and behavioral \\ outcomes is likely to shift during the recovery process. The current study examined the \\ relations among these constructs across three groups of women between the ages of 18- \\ 35: those with an active ED $(n=78)$, those in self-defined ED recovery $(n=130)$, and \\ those without clinically significant disordered eating $(n=178)$. Participants completed \\ measures of thin-ideal internalization, body, eating, and exercise social comparison, body \\ dissatisfaction, and disordered eating in one online session. The hypothesized model fit \\ poorly when all paths were constrained to be equal across the three groups, and \\ significantly improved when parameters were freely estimated. For participants in ED \\ recovery, the link between thin-ideal internalization and social comparison was no longer \\ statistically significant, highlighting shifts in social-cognitive processes and a disruption \\ in the sociocultural model of disordered eating for women in recovery. \\ Keywords: social comparison, thin-ideal internalization, recovery, eating disorder
}




\section{Literature Review}

Thin-ideal internalization is a social-cognitive construct referencing the degree to which an individual subscribes to and aims to reach society's "ideal" body type (Thompson, Heinberg, Altabe, \& Tantleff-Dunn, 1999). Thin-ideal internalization has been identified as the strongest predictor of body dissatisfaction among adolescent girls and young women (Culbert, Racine, \& Klump, 2015). While thin-ideal internalization was initially thought to occur with less frequency and intensity in non-European or American cultures, more recent research has found equivalent levels across women and girls from a variety of racial and ethnic backgrounds including Latinas and AsianAmericans, with the exception of Black women with high levels of internalized ethnic identity, who express lower levels of thin-ideal internalization (Rakhkovskaya \& Warren, 2014). Both persistent exposure to and immediate reminders of these societal and cultural standards (Frederick, Daniels, Bates, \& Tylka, 2017) lead to increases in body dissatisfaction and disordered eating. Given the potent role thin-ideal internalization has on disordered eating outcomes and the development of clinically significant EDs (Thompson \& Stice, 2001), this construct has been targeted by dissonance based, medialiteracy, and peer education ED prevention models (Breithaupt, Eickman, Byrne, \& Fischer, 2017; Stice, Mazotti, Weibel, \& Agras, 2000; Wade et al., 2017).

The idealization of an unrealistically thin body and, in turn, dissatisfaction with one's own body, is an important pathway predicting the development of disordered eating pathology. Several social-cognitive mediators have been identified as key links between thin-ideal internalization and the development of disordered eating pathology. Of these, the most robust, as examined in experimental, correlational, and longitudinal research, is 
social comparison (Fitzsimmons-Craft et al., 2016; Want, 2009). Specifically, comparing oneself to media images, familiar, and unfamiliar peers all have damaging short-term consequences for body satisfaction (Myers \& Crowther, 2007).

Festinger (1954) proposed social comparison theory as a mechanism by which individuals assess their position in society, and use that assessment to motivate change and preserve self-esteem. As initially conceptualized, social comparison theory features two types of comparison, upward (comparing to a more successful target), and downward (comparing to a less successful target). While downward comparisons are thought to be protective within the social comparison framework, this does not hold true in regard to body dissatisfaction and disordered eating (Lin \& Soby, 2016; Saunders \& Eaton, under review a). Not only are both upward and downward appearance comparisons predictive of the development of higher rates of eating pathology, but both types of comparisons have the potential to hinder and help the ED recovery process (Saunders \& Eaton, under review b).

Moreover, the tendency to engage in social comparison is predictive of future disordered eating behavior (Arigo, Schumacher, \& Martin, 2014; Fitzsimmons-Craft, 2017). College-aged women who initially scored below the clinical cut-off on the Eating Disorder Examination Questionnaire (EDE-Q, Fairburn \& Beglin, 1994), yet received clinically-significant scores two months later, also exhibited more frequent self-reports of upward appearance-related social comparisons at baseline compared to women whose eating patterns did not change between testing sessions (Arigo et al., 2014). Moreover, ecological momentary assessment studies show that the act of engaging in a social 
comparison often results in subsequent body dissatisfaction and disordered eating (Fitzsimmons-Craft, 2017).

In the cycle of disordered eating, thin-idealization leads an individual to pursue a thinner body; to accomplish this, individuals begin to rely on social comparison, comparing their body, eating, and exercise habits with those of others, to assess whether they are progressing towards their desired goal (Fitzsimmons-Craft, 2011). Multiple sociocultural models of disordered eating have explored the relationship between thinideal internalization, social comparison, and disordered eating outcomes (FitzsimmonsCraft et al., 2014; Lindner, Tantleff-Dunn, \& Jentsch, 2012; Tylka \& Sabik, 2010). In each model, the tendency to engage in body, eating, and/or exercise-related social comparisons functioned as the mechanism by which thin-idealization was translated into disordered eating outcomes.

To date, very little research exists examining social comparison during ED recovery. The developing body of work on this topic to date highlights the varied roles comparisons can have on the recovery process (Saunders \& Eaton, under review b), with certain comparisons, derived from a recovery positive mindset, having the potential to support recovery rather than disordered eating (Saunders, Eaton, \& Fitzsimmons-Craft, under review). The one other study investigating social comparison during the ED recovery process found that the tendency to engage in virtual comparisons (i.e., via social media) with others in ED treatment was related to increases in ED psychopathology and general clinical impairment (Saffran et al., 2016). No research to date has examined the relationship between thin ideal internalization, body, eating, and exercise social comparisons, and eating pathology during ED recovery. 


\section{Current Study}

The current study sought to fill this identified gap in the literature by probing the indirect effects of thin-ideal internalization on disordered eating outcomes through body, eating, and exercise comparison tendencies. We examined these indirect effects in a group of women without clinical EDs to replicate prior findings (Fitzsimmons-Craft et al., 2014; Lindner, Tantleff-Dunn, \& Jentsch, 2012), women with clinical EDs, and women in recovery. Other social-cognitive processes during this time, such as body surveillance (Fitzsimmons-Craft, Bardone-Cone, \& Kelly, 2011), perfectionism (Bardone-Cone et al., 2010a), and self-concept (Bardone-Cone et al., 2010b) shift during recovery, with decreases bringing the mean score in fully recovered individuals statistically similar to that of healthy controls. Changes in the way some social comparisons are used to support the recovery process also occur during this time (Saunders, Eaton, \& Fitzsimmons-Craft, under review). Given these identified changes, we wanted to examine the degree of change in the relations among the social-cognitive constructs of thin-ideal internalization and social comparison with body dissatisfaction and disordered eating (see Figure 2). 


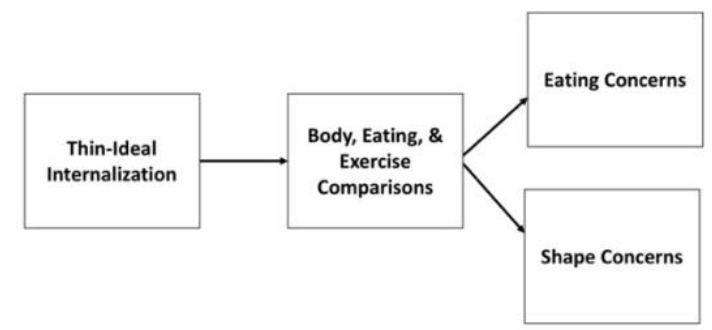

Figure 2. Hypothesized sociocultural model of disordered eating

Namely, we anticipated the connections among thin-ideal internalization, social comparison, and disordered eating outcomes would be shifting for women with clinical EDs, as other mechanisms are driving the disorder once it is entrenched. These women deeply subscribe to the thin ideal, but their social comparison tendencies may be more directly related to ED cognitions than the cultural pursuit of thinness. This would be demonstrated through weaker relations between thin idealization and social comparison. Further, we predicted there would no longer be an indirect effect of thin-ideal internalization on body dissatisfaction and disordered eating through social comparison tendencies for women in ED recovery, as body, eating, and exercise comparisons lose their classically-ascribed purpose during recovery (Saunders \& Eaton, under review b).

\section{Method}

To test the relationship between thin-ideal internalization, social comparison, and disordered eating in women without EDs, women with EDs, and women in ED recovery, we recruited participants via social networking sites (Facebook and Instagram), the university undergraduate study pool of a large, Southeastern public university, or referrals from a qualitative study on ED recovery (Saunders \& Eaton, under review b; 
Study 1). Participants from the university undergraduate study pool received course extra credit in exchange for their time; participants from other sources did not receive compensation. The study recruitment advertisement invited all women between the ages of 18-35, regardless of whether or not they self-identified as struggling with or being in recovery from an eating disorder, to participate in a study to help researchers better understand the similarities and differences in the way women with EDs, in recovery from an ED, or without disordered eating think. All participants provided written informed consent, and all procedures were approved by the university's Institutional Review Board. A portion of the current data (the ED recovery sub-sample) was used to validate the body, eating, and exercise social comparison measure for women in ED recovery (Saunders, Eaton, \& Fitzsimmons-Craft, under review; Study 2).

\section{Participants}

The sample consisted of 386 women (34\% from the university sample) between the ages of $18-35\left(M_{\text {age }}=25.59, S D=4.81\right)$. At the start of the survey, participants were asked if they had ever been diagnosed with a clinical ED. If they answered yes, they were then asked if they considered themselves to be recovered or in recovery. This allowed for the creation of three groups (healthy control, active ED, and recovery). As some participants may have met ED criteria without ever having been diagnosed or treated (Hart, Granillo, Jorm \& Paxton, 2011), or may have considered themselves to be in recovery or recovered despite high levels of eating pathology, participants whose global EDE-Q scores fell outside of two standard deviations of community norms (Mond, Hay, Rodgers, \& Owen, 2006) were regrouped. In doing so, 23 participants who did not consider themselves to have an ED were added to the active ED group, as were 46 
women who had considered themselves to be in recovery, as they failed to meet the minimum behavioral remission standards. This resulted in three uneven groupings: healthy control $\left(H C ; n=178 ; M_{\text {age }}=25.36, S D=4.47\right)$, active $\mathrm{ED}\left(E D ; n=78 ; M_{\text {age }}=\right.$ $25.79, S D=5.40)$, and recovery $(R C ; n=78 ;$ Mage $=25.85, S D=4.95)$.

Mean age did not differ significantly across groups, $F(2,384)=.312, p<.73$. Selfidentified race and ethnicity were not distributed evenly across the grouping, $\chi^{2}(12)=$ $33.15, p<.001$. The $H C$ group was $42.4 \%$ non-Hispanic White, $36 \%$ Hispanic White, 14.4\% Black, 4.3\% Multi-racial, 2.2\% Asian, and 0.7\% “Other." The ED group was 57.1\% non-Hispanic White, 31.7\% Hispanic White, 4.8\% Black, 3.2\% Multi-racial, 1.6\% Native American, and 1.6\% Asian. Lastly, the RC group was 74.4\% non-Hispanic White, 23.1\% Hispanic White, 1.3\% Multiracial and 1.3\% "Other." There were also discrepancies in highest education level completed (one proxy for socioeconomic status) across the groups, with individuals with active EDs less likely to have completed advanced education. About half (49.6\%) of the healthy control group had received at least a bachelor's degree, compared to $41.3 \%$ of individuals with active EDs and $60.2 \%$

of individuals in ED recovery. All participants completed all measures, regardless of their diagnostic or symptom history.

\section{Measures}

Body, Eating, and Exercise Comparisons. To quantify body-, eating-, and exercisecomparison tendencies, participants completed the revised Body, Eating, and Exercise Comparison Orientation Measure (BEECOM, Saunders, Eaton, \& Fitzsimmons-Craft, under review). The initial measure was developed for a non-clinical female sample. The measure was revised to suit the unique comparison tendencies of women in ED recovery. 
The revision required the elimination of items relating to health and junk food, as discourse around and use of these terms shifts during the ED recovery process (LaMarre \& Rice, 2016). The revised measure consists of fourteen items related to food, appearance, and exercise comparison tendencies, rated on a 7-point Likert scale with response options varying from never (1) to always (7). Higher scores are indicative of greater social comparison tendencies. The internal consistency was high for each of the three groups ( $\mathrm{HC} \alpha=.95 ; \mathrm{ED} \alpha=.95 ; \mathrm{RC} \alpha=.96)$.

Thin Ideal Internalization. The Thin Ideal Internalization subscale of the most updated Sociocultural Attitudes Towards Appearance Questionnaire (version 4; SATAQ-4, Schaefer et al., 2015) was administered to quantify the degree to which participants had internalized the thin-ideal as propagated by mass media and culture. This measure is best suited to quantify personal goals of thinness (Thompson, Schaefer, \& Dedrick, 2018). The subscale consists of five items rated on a five-point Likert scale, from definitely disagree (1) to definitely agree (5). Higher scores are representative of greater thin-ideal internalization. The internal consistency of this measure was adequate for the $\mathrm{HC}(\alpha=$ $.71)$ and $\mathrm{RC}(\alpha=.78)$ groups, and low for the ED group $(\alpha=.66)$. This suggests, consistent with prior clinical work (i.e. Treasure, Stein, \& Maguire, 2015), that in the depths of a clinical ED, there are other factors maintaining the disorder aside from pursuit of thinness.

Body Dissatisfaction and ED Symptomology. To quantify body dissatisfaction and ED symptomology, the Eating Disorder Examination Questionnaire (EDE-Q; Fairburn \& Beglin, 1994, 2008), the leading self-report measure in ED research and clinical practice, was administered. This scale consists of 20 items assessing frequency of thoughts and 
behaviors as rated on a 7-point Likert scale, ranging from no days (0) to everyday (6) over the course of the past 28 days. The scale also asks an additional eight questions assessing the degree to which an individual experienced certain disordered cognitions about food body, and weight, rated on a 7-point scale ranging from not at all (0) to markedly (6). The current study used two of the four EDE-Q subscales: (1) shape concern (to quantify body dissatisfaction) and eating concern (emotions \& cognitions related to eating, to quantify disordered eating). The internal consistency of both the shape subscale ( $\mathrm{HC} \alpha=.84 ; \mathrm{RC} \alpha=.91 ; \mathrm{ED} \alpha=.76)$ and eating concern subscale ( $\mathrm{HC} \alpha=.72 ; \mathrm{RC} \alpha=$ $.78 ; \mathrm{ED} \alpha=.72$ ) were adequate for all samples.

\section{Analytic Plan and Data Screening}

Descriptive and preliminary analyses were conducted using SPSS 23.0, and the subsequent path analysis was conducted using MPlus 7.0 (Múthen \& Múthen, 2012). Data were first evaluated for skewness, kurtosis, missingness, and the presence of univariate or multivariate outliers. The data for the $\mathrm{HC}$ sub-sample were not missing at random (Little's MCAR $\left.\chi^{2}(62)=99.86, \mathrm{p}<.002\right)$. Missing data were imputed in SPSS using Expectation-Maximization (EM), shown to produce relatively unbiased estimates for item-level missing data (Enders, 2003). Preliminary descriptive and inferential analyses (ANOVA \& Chi-Square) were conducted to examine group level differences. To thoroughly and robustly evaluate model fit, multiple fit indices were used (Hu \& Bentler, 1999).

Data were analyzed via multi-group path analysis. The structural invariance of the model across the three groups $(H C, E D, R C)$ was evaluated by testing an unconstrained model, in which the parameters were estimated freely. The fit of the unconstrained model 
was compared to the fit of a constrained model in which the paths were forced to be equal across groups. A Chi-Square difference test was conducted using the Chi-square goodness of fit test statistic from the respective models to assess whether the model fit the data significantly better when the paths were freely estimated, compared to when the paths were constrained. Once path estimates were calculated, indirect model effects were examined using the joint-significance paradigm, computed using RMediation software (Tofighi \& MacKinnon, 2011). This method was chosen as it both minimizes Type I error rates and maximizes statistical power (MacKinnon et al., 2002). Within this framework, the indirect effect is significant if the corresponding 95\% confidence interval (CI) does not contain zero.

\section{Results}

\section{Sample Characteristics}

Of the active ED sample, $65 \%$ of women reported receiving a primary diagnosis of anorexia nervosa (AN; typical or atypical), $12.5 \%$ reported receiving a primary diagnosis of bulimia nervosa $(\mathrm{BN}), 12.5 \%$ reported receiving a primary diagnosis of binge eating disorder (BED), and 10\% reported receiving a primary diagnosis of otherwise specified feeding and eating disorder (OSFED). The distribution was similar in the recovery group, as $57 \%$ of participants within this group reported being in recovery or having recovered from AN (typical or atypical), 19\% reported having recovered from $\mathrm{BN}, 11.4 \%$ reported having recovered from $\mathrm{BED}$, and $12.7 \%$ reported having recovered from OSFED. However, these distributions were surprising, as prior research indicates BED and BN to be more prevalent than AN (Stice, Marti, \& Rohde, 2013), and may partly reflect the fact that individuals with AN are more likely to receive a clinical 
diagnosis and intensive treatment for weight loss due to medical abnormalities (Hart et al., 2011).

\section{Group Inferential Statistics}

A series of one-way ANOVAs, with group $(H C, E D, R C)$ as the independent variable revealed group mean-level differences in thin ideal internalization $(F(2,383)=$ $57.23, p<.001)$, body, eating, and exercise comparisons $(F(2,383)=84.79, p<.001)$, shape concern $(F(2,383)=85.42, p<.001$, and eating concern $(F(2,383)=140.62, p$ $<.001)$. Post-hoc comparisons highlight significant differences across all three groups (see Table 2), with the exception of thin-ideal internalization. Surprisingly, for thin ideal internalization, average scores were not significantly different for the ED and RC groups $(p>.05)$.

Scale or Subscale

Thin Ideal Internalization

Eating Concern

Shape Concern

$\begin{array}{ccc}\text { Group } & \boldsymbol{M} & \boldsymbol{S} \boldsymbol{D} \\ \text { HC } & 2.93 & 0.82 \\ \text { RC } & 3.77 & 0.73 \\ \text { ED } & 3.88 & 0.91 \\ \text { HC } & 48.83 & 16.68 \\ \text { RC } & 66.22 & 16.15 \\ \text { ED } & 75.29 & 16.1 \\ \text { HC } & 0.89 & 0.82 \\ \text { RC } & 1.54 & 1.03 \\ \text { ED } & 3.05 & 1.07 \\ \text { HC } & 2.01 & 1.14 \\ \text { RC } & 2.62 & 1.22 \\ \text { ED } & 4.03 & 0.98\end{array}$

Table 2. Mean scores on each scale or subscale across groups. All means are significantly different from one another $(* * p<.01)$ aside from the $R C \& E D$ Thin Ideal Internalization scores. 


\section{Multi-group Path Analysis}

When the model path estimates were forced to be equal across all three groups, the model fit the data poorly: RMSEA $=.211,90 \% \mathrm{CI}[.149, .277], p$-close $=.359, \mathrm{CFI}=$ $.777, \mathrm{TLI}=.665, \mathrm{SRMR}=.13$, and $\chi^{2}(12)=46.504, p<.001$. The chi-square difference test indicated that model fit significantly improved when the model path estimates were freely estimated, $\boldsymbol{\Delta} \chi^{2}(6)=37.741, p<.001$. The unconstrained model fit the data well: $\mathrm{RMSEA}=.06,90 \% \mathrm{CI}[.000, .139], \mathrm{CFI}=.991, \mathrm{TLI}=.972, \mathrm{SRMR}=.043$, and $\chi^{2}(6)=$ 8.76, $p<.19$. As illustrated in Figures 3 and 4, the predicted relationships within the sociocultural model of disordered eating held for the HC group and weakened for the ED group. Also as predicted, there is not an indirect relationship between internalization of the thin ideal to body dissatisfaction and disordered eating through social comparison tendencies for women in ED recovery (see Figure 5). The model explains virtually none of the variance in body, eating, and exercise comparisons for women in ED recovery, yet does explain twenty percent of the variance in eating and shape concerns, indicating that body, eating, and exercise comparisons in recovery stem from areas outside of thin-ideal internalization. 


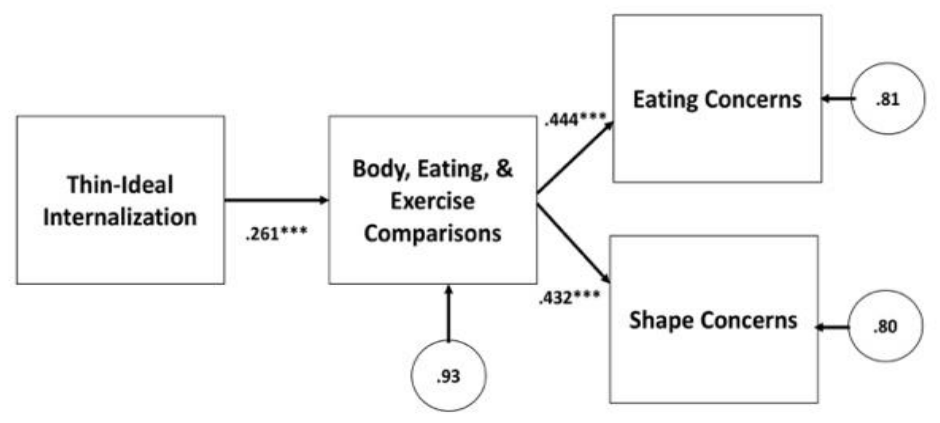

Figure 3. Sociocultural model of disordered eating for healthy control group

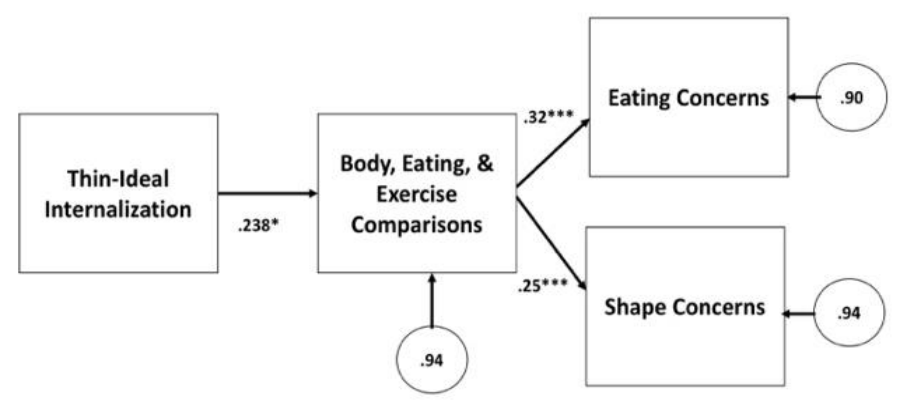

Figure 4. Sociocultural model of disordered eating for eating disorder group 


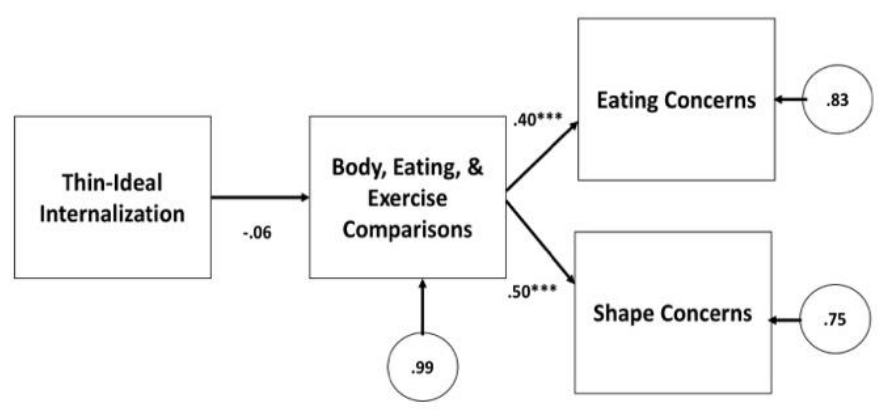

Figure 5. Sociocultural model of disordered eating for recovery group

\section{Indirect Effects}

Replicating prior findings (Fitzsimmons-Craft, 2014, 2016; Keery, van den Berg, \& Thompson, 2004), we found significant indirect effects between internalization of the thin-ideal and eating and shape concerns for the HC group (see Table 3). Body, eating, and exercise-related social comparisons no longer mediated the relationship between thin-ideal internalization and shape concerns for the ED or RC groups, nor the relationship between thin-ideal internalization and eating concerns for the $\mathrm{RC}$ group.

\begin{tabular}{|c|c|c|}
\hline Relations & Group & Indirect Effect \\
\hline \multirow{3}{*}{$\begin{array}{c}\text { Thin Ideal---> Shape } \\
\text { Concerns }\end{array}$} & $\mathrm{HC}$ & $.116, \mathrm{SE}=.036,95 \%$ CI $[.05, .193]$ \\
\hline & ED & $.058, \mathrm{SE}=.04,95 \% \mathrm{CI}[-.002, .152]$ \\
\hline & $\mathrm{RC}$ & $-.024, \mathrm{SE}=.031,95 \% \mathrm{CI}=[-.088, .035]$ \\
\hline \multirow{3}{*}{$\begin{array}{c}\text { Thin Ideal---> Eating } \\
\text { Concerns }\end{array}$} & $\mathrm{HC}$ & $.113, \mathrm{SE}=.035,95 \%$ CI $[.049, .187]$ \\
\hline & ED & $.08, \mathrm{SE}=.04,95 \%$ CI $[.01, .176]$ \\
\hline & $\mathrm{RC}$ & $-.03, \mathrm{SE}=.04,95 \% \mathrm{CI}=[-.11, .04]$ \\
\hline
\end{tabular}

Table 3. Indirect effects between thin ideal internalization and shape and eating concerns by group. Bold indicates a significant indirect effect. 


\section{Discussion}

The current study examined the fit and relationships of the sociocultural model in three-subsamples: a sample of women with no ED history and no current clinical-levels of ED pathology $(H C)$, a sample of women with an active $\mathrm{ED}(E D)$, and a sample of

women in ED recovery $(R C)$, both based on self-report and EDE-Q scores. As predicted and previously demonstrated in the literature, there was an indirect effect of thin-ideal internalization on body dissatisfaction and disordered eating for the $H C$ group through one's tendency to engage in body, eating, and exercise social comparisons. Likewise, these interrelations weakened for the $E D$ group, and were no longer statistically significant for the $R C$ group.

These results underscore an important change that happens during the ED recovery process. While thin-idealization levels and social comparison tendencies still remain higher for these women than the healthy control group, the purpose these constructs serve and the role they play in eating, food, and appearance-related choices shifts with the return of normalized weight, eating, and the psychosocial correlates that accompany these physical changes (Bardone-Cone et al., 2009).

Prior research identifies several predictors of sustained recovery. However, these group-level differences have only been examined retrospectively and very few factors have been consistently identified as predictors of sustained ED recovery (Lock et al., 2013). Some predictors of recovery, such as the personality dimension extraversion (Levallius, Roberts, Clinton, \& Norring, 2016) and high levels of impulsivity (Zerwas et al., 2013) are not easily modifiable. Motivation to recover (Carter et al., 2012), high levels of social support (Linville, Brown, Sturm, \& McDougal, 2012), acceptance of 
positive and negative emotions and of the need for self-compassion (Butryn et al., 2013; Kelly, Carter, Zuroff, \& Borairi, 2013), and effective coping with negative emotional experiences (Federici \& Kaplan, 2008) are several of the malleable predictors that have been probed at the group level as indicators of successful treatment experiences and long term recovery. The current findings add support to shifts in the relationship between thinidealization and social comparison as malleable predictors of recovery. Notably, the constructs investigated here involve multiple variables that cannot be studied in isolation, and likely coact bi-directionally (Tiggemann, 2011). Given the cross-sectional design employed here, future research needs to examine changes in these constructs prospectively, and using a person-centered data analytic approach, to best understand how the interrelations between thin-ideal internalization, social comparison, and disordered eating outcomes change over time for women in recovery, and how to best therapeutically target these constructs in tandem to promote sustained recovery outcomes.

Future research should also examine potential similarities and differences in model relationships in women from varied ethnic and racial backgrounds. For example, thin-ideal internalization does not explain much of the variance in ED pathology for Black women (Capodilupo, 2015). The role of appearance related social comparison on disordered eating outcomes for cultural and ethnic minorities is in the nascent stages of exploration. More recently, frequent downward appearance related comparisons were found to correlate with higher eating, weight, and shape concerns for Hispanic women, and to greater body dissatisfaction for Asian and White women without clinical EDs (Rancourt, Schaefer, Bosson, \& Thompson, 2015; Schaefer et al., 2015). Thus, cultural or 
racial variations in the interrelations observed in the current study merit further investigation.

In using an online, convenience sample, the current study has several limitations. Participation was only open to individuals who viewed the online advertisement and link, or were personally invited by the investigators based on participation in prior studies. While the sample was diverse in ethnicity and socioeconomic status, it is important to extend these findings to a more heterogeneous sample. Our sample was also transdiagnostic, and while there is significant diagnostic cross-over and shared symptomology and cognitions among all EDs, it is possible that these constructs coact differentially depending on primary ED diagnosis.

These limitations notwithstanding, the current study highlights a critical change in how the sociocultural model of disordered eating operates during the clinical ED and recovery process, highlighting important pathways for prevention and intervention. Although the current study presents these interrelations at a single point within the recovery time-course, this work identifies an important difference across the three ED groups, accentuating the importance of better understanding the nuances to these constructs for both ED prevention. 


\title{
STUDY IV \\ DISORDERED SOCIETY: \\ WOMEN IN EATING DISORDER RECOVERY ADVISE \\ POLICYMAKERS ON CHANGE
}

\begin{abstract}
This qualitative study draws on a photo-elicitation method ("PhotoVoice") and semi-structured interviews to examine the key areas stakeholders (30 young women between the ages of 18 and 35 in eating disorder (ED) recovery) identify as meaningful venues of policy-based change. Photography and the accompanying narratives capturing personally-meaningful social, cultural, and systemic influences on their recovery were shared with the research team. Photographs and interviews were examined for policy implications using thematic analysis, and six areas of improvement emerged: media, healthcare practice and access, health insurance reform, education, objectification of the female body, and mental health stigma. Further implications for reform are discussed.
\end{abstract}

Keywords: eating disorder, policy,, health insurance reform, media, objectification 


\section{Literature Review}

"And I think in order to start really working on eating disorders for individuals, treatment for individuals, we really have to focus on treating society. Because, like, society as an entity needs some residential [treatment] right now." (Steph, age 31)

Eating disorders (EDs) are a significant public health issue in the U.S., affecting $13 \%$ of all young adult women (Stice, Marti, \& Rohde, 2013). Eating disorders have the highest mortality rate among mental illnesses and nearly $30 \%$ of sufferers remain symptomatic at ten-year follow-up (Keel \& Brown, 2010), due in part to treatment barriers such as cost and access, and limitations in the effectiveness of many common treatment options currently available (Kazdin, Fitzsimmons-Craft, \& Wifley, 2017). Frontline medical providers, particularly primary care physicians, are not well-trained in identifying EDs (Linville, Benton, O’Neil, \& Sturm, 2010), and when individuals do seek medical and psychological support for disordered eating, the vast majority do not receive evidence-based care (Harvey \& Gumpart, 2015), or receive care delivered without fidelity to core components (Shaffran et al., 2009).

While the American Psychiatric Association (Yager et al., 2010) and the American Dietetic Association (Ozier \& Henry, 2011) have offered treatment guidelines and recommendations for EDs, progress in obtaining insurance coverage for the recommended course of care has been slow and the current system fails to reduce the individual and public health burden (Mond, 2016). Very few internal medicine doctors are trained to identify disordered eating and provide referrals to specialists (Vetter et al., 2007), highlighting a major gap between research and practice, and an opportunity for 
change. These issues have been systemically examined for decades (i.e., Sigman, 1996), yet barriers to insurance and adequate treatment persist (Kazdin et al., 2017).

Given the vast and multifaceted costs associated with the hardship of EDs for both patients and society (Whiteford et al., 2013), it is critical to identify ways to improve ED recovery pathways and outcomes via empirically-informed policies designed to improve access and reduce barriers to care (e.g., Anna Westin Act, H.R. 2515; Helping Families in Mental Health Crisis Act, H.R. 2646). The Anna Westin Act (2015) is the first piece of ED-related legislation to be approved by Congress in U.S. history, and requires the U.S. Department of health and Human Services to make ED-related educational information freely available, and prohibits insurance companies from denying coverage to an individual based on a mental health diagnosis. However, there has been little progress towards expanding this act, which represents just a beginning for social-level change in this area. In addition, there is scant limited research on EDs that can be easily or directly translated into policy and action to reduce the burden of EDs on both the individual and society (Austin, 2016). More research is needed to strengthen national ED-related health and social policies. The purpose of this paper is to provide an in-depth, participant-based set of recommendations, guided by feminist theory and social justice aims.

\section{Objectified Body Consciousness and the Development of Disordered Eating}

The current body of research implicates sociocultural pressures for thinness and internalization of the thin ideal as the most salient predictors of disordered eating and the development of clinical EDs (Culbert, Racine, \& Klump, 2015). Exposure to these environmental factors, and to society's patriarchal views on women and the female body 
(i.e., sexual objectification) lead to the development of objectified body consciousness (OBC; Fredrickson \& Roberts, 1997; Moradi \& Varnes, 2017). Women who are hyperfocused on their own appearance, as is common with women diagnosed with EDs, are more aware of both their own and other women's physical appearance, and thus engage in frequent body comparisons. The act of comparing oneself against others likely both (1) perpetuates the objectification of other women's bodies and (2) reinforces OBC tendencies, situating the woman who is engaging in comparisons as both the source and target of objectification (Tylka \& Sabik, 2010). This cycle of comparison, selfobjectification, and disordered eating is maintained and intensified by sociocultural factors promoting thin idealization (Lindner, Tantleff-Dunn, \& Jentsch, 2012).

Per objectification theory (Fredrickson \& Roberts, 1997), cultural practices of sexual objectification, such as sexualized gazing and media portrayals of women's bodies, lead to $\mathrm{OBC}$, in which women place greater emphasis on their appearance than on their internal attributes. This over-focus leads women to disregard their own physical cues and attempt unrealistic body-change strategies. As a result of adopting an observer perspective on oneself and internalizing messages regarding the malleability of the body to achieve cultural expectations, OBC manifests through body surveillance, body shame, and appearance control beliefs (McKinley \& Hyde, 1996). Each of these three components has been found to support the development and maintenance of the pursuit of thinness typically observed in women with EDs (Calogero, Davis, \& Thompson, 2005). Self-objectification, or OBC, meets the definition of a harmful cultural practice as delineated by the United Nations (1995), as it has dangerous health consequences, arises from and is justified by gender-based power differentials from which men profit, and 
generates stereotypes that stall the development of girls and women (Calogero, TantleffDunn, \& Thompson, 2011).

Self-objectification highlights appearance control, rather than action against oppressive cultural forces, as effective currency in the societal system of sexual objectification and gender inequality (Calogero \& Tylka, 2014). In controlling one's own appearance instead of acting against a sexist and patriarchal system, self-objectifying tendencies serve to defend the status-quo (Calogero, 2013). Alternatively, to stimulate lasting personal and social change, the lens of self-objectification needs to be re-focused toward a more holistic view of the self and of women in general, that will undermine the beliefs that keep this system in tact (Calogero \& Tylka, 2014). At the personal level, this re-focusing likely happens during ED recovery, during which time many social-cognitive changes occur. Women in recovery may therefore be well positioned to identify opportunities for re-focusing our view of and approach to women and EDs at the cultural and societal levels.

\section{PhotoVoice: A Novel Method for Research, Advocacy, and Change}

While empirically based, most existing literature on self-objectification and disordered eating, and the few existing policy recommendations to prevent and intervene on disordered eating, have been directed and guided by the scientific, medical, and academic communities, with limited voice to the individuals most affected, profoundly restricting the depth of our knowledge and capacity for change (Ridge, 2008). One way to address this gap is through participatory action research (Morrison \& Lilford 2001), which invites participants to co-create the research protocol and policy agenda. Recent shifts in research priorities, such as the development of the Patient Centered Outcomes 
Research Institute, have placed increased emphasis and importance on the voices of the stakeholders and others most directly impacted by a mental health issue (Frank, Basch, \& Selby, 2014). However, there is a dearth of patient centered studies for individuals in ED recovery.

Participatory action research (PAR) frameworks function not only to increase understanding of a particular problem, but also to collect information for action and advocacy (Cornwall \& Jewkes 1995) and place the power for directing change in the hands of the affected community. Participatory action research frameworks differ from conventional social science methodologies by involving participants directly in research goals, planning, and design, and placing heavy emphasis on community action (Kemmis \& McTaggart, 2005). Participant-centered research has led to recent changes in cancer screening techniques, childhood asthma prevention, firearms violence, and early childhood education (Woolf, Zimmerman, Haley, \& Krist, 2016). Over the last several decades, few researchers have begun to draw from this research framework to improve ED prevention (i.e., Piran, 2001) and better understand the ED recovery process (LaMarre \& Rice, 2016a), and much room remains for additional exploration.

PhotoVoice is one PAR framework especially well-suited to examining ED recovery. The PhotoVoice method has three complimentary goals: (1) provide a platform for participants' lived experiences and viewpoints, (2) involve both the culture and community to exchange ideas surrounding key themes that emerge via photographic art and oral exploration, and (3) ensure that the information is not confined to the academic and scientific communities (Wang \& Burris 1994, 1997). The method involves the use of photography and accompanying narratives to explore social issues. To date, PhotoVoice 
has been used to examine a broad array of systemic problems, including homelessness, disability, illness, war, and violence (Hegenraher, Rhodes, Cowan, Bardhoshi, \& Pula 2009). PhotoVoice has been highlighted as an appropriate method for exploring sensitive topics, including body image, because participants are recognized as the experts surrounding a given issue, and are able to provide information and insight at their own pace and comfort level (Brunsden \& Goatcher 2007). The PhotoVoice method has been correlated with multiple mental and physical health-promoting outcomes, such as empowerment and improved self-efficacy (Foster-Fishman et al., 2005). Notably, PhotoVoice projects have led to health policy changes in a variety of areas, including obesity prevention at the local level, improved access to handicapped parking, and reduced tobacco sales (Sanon, Evans-Agnew, \& Boutain 2014).

\section{Current Study}

Given the identified gaps in the literature around participant-centered ED recovery research and research with direct policy implications, the current study used PhotoVoice to collect and synthesize the insight stakeholders bring to this issue, for the purpose of informing policy and practice. Previous research suggests PAR projects offer a unique perspective unable to be captured through the use of typical quantitative or basic qualitative methods. We were especially interested in the suggestions women in ED recovery would have for policymakers regarding the social and cultural forces that can make recovery challenging. Specifically, the current study sought to examine reform suggestions and highlight areas of change that are most significant for individuals directly touched by these disorders. 


\section{Participants}

\section{Method}

The current data are part of a larger PhotoVoice qualitative data set on perspectives of women in ED recovery, a portion of which has been previously analyzed for other research questions (Saunders \& Eaton, under review). Women self-identifying as in ED recovery $(n=30)$ from the northeastern U.S. $(n=6)$ and the southeastern U.S. $(n=24)$ participated, following informed written consent. Women in self-defined ED recovery between the ages of 18 -35 were invited to participate $(M=23.37, S D=4.35)$. All participants were U.S. citizens, and had lived in the U.S. for at least five years. The sample was racially and ethnically diverse, with the majority self-identifying as White Hispanic $(n=17,56.67 \%)$. One-third of participants identified as White non-Hispanic $(n$ $=10)$, two identified as Black Hispanic (6.67\%), and one as Indigenous North American $(3.33 \%)$. Contributors represented both convergent and diverse views held by community members within two areas of the U.S.

\section{Procedure}

Participants were recruited via multiple methods: the distribution of paper flyers across the campus of a large, Southeast, Hispanic-serving public university; electronic advertisements on social media platforms; and snowball sampling. After learning about the study goals and providing informed consent for participation and use of photographs, participants were presented with the study prompt (see Saunders \& Eaton, under review):

"Give us insight into your recovery world. What are the social and cultural pressures and expectations in your world that support you in your recovery, and what are those that are challenging for you in your recovery? What role 
does comparison to others play in making recovery more challenging? What types

of comparisons serve to support your recovery process? Please take photos of the

things you encounter in your everyday life to answer these questions and help

me to better understand your recovery process"

Participants had seven days to creatively respond to the prompt by taking as many

photographs as they deemed necessary to best capture their experiences. Participants had the option of using a disposable camera offered by the research team. However, all photos were taken on smartphone cameras. The number of photographs taken by each participant varied widely, from four to $28(M=10.13, S D=5.56)$. In-person semistructured interviews reviewing and discussing the photos were conducted between May and November 2017, one-on-one with the first author $(n=16)$ or the trained graduate research assistant $(n=14)$. The dissertation author jointly trained the graduate research assistant, in-person and by having the graduate research assistant review previously completed interviews. Participants chose to hold their interview in a variety of locations (private on-campus office space, $n=21$; coffee shop, $n=7$; park, $n=2$ ). The interviews ranged in length from 30 minutes to one hour and 20 minutes $(M=49 \min 20 \mathrm{sec}, S D=$ 13 min $12 \mathrm{sec}$ ). Thirty percent of participants shared older photographs in conjunction with new photos they took for the project.

The semi-structured interview began with rapport building between the interviewer and participant, and the sharing of brief demographic and ED background information. Participants were then asked to reveal the photos they brought, and answered a series of questions about each one. The semi-structured interview protocol featured open-ended questions, allowing the participant to determine the amount and 
content of the information she wished to share, and to defer questions pertaining to areas of recovery she was uncomfortable sharing with the interviewer. The semi-structured interview used the the SHOWeD technique (Hergenrather, Rhodes, Cowan, Bardhoshi, \& Pula, 2009) to probe participants about each of their photos. Corresponding to guidelines established for Photovoice work, participants (S) discussed what can be seen in the photo, (H) expressed what is happening, or the potentially unseen tale behind the photo, (O) connected the picture to our lived experiences, (W) highlighted why things are this way, and (D) discussed ideas for a strong solution to the underlying issue captured in the picture. At the end of the interview, participants had the opportunity to reflect on their recovery process, offer direct suggestions to policymakers and the government, and ask any questions they had about the study process. With participant consent, interviews were documented on a mini Sony ICD-UX71 digital voice recorder. Participants selected a pseudonym, which is used throughout the manuscript, to preserve anonymity. Participants received a $\$ 25$ e-gift card as compensation for their time. All procedures were approved by the university's Institutional Review Board.

\section{Data Analysis}

A team of five undergraduate research assistants and one graduate research assistant transcribed the 30 interviews. A random selection of six interviews (20\%) were evaluated by an independent transcriber for accuracy. The primary goal of the overarching study was to examine social-cognitive (i.e., social comparison and selfobjectification) processes during women's ED recovery journeys, particularly to identify the types, targets, and effects of social comparison for this population. After viewing the photos the participants shared and conducting the semi-structured interviews, it became 
clear that this work has important policy implications and recommendations; hence, common to data interpretation from PhotoVoice projects (Han \& Oliffe, 2016), the data were re-examined using thematic analysis to extract patterns of meaning (Braun \& Clarke, 2006) regarding participant health and social policy suggestions.

The research team took an iterative approach to coding the interviews. After reviewing all thirty interviews, the first author and a graduate research assistant met to discuss all of the possible policy-related content. The first author then developed an initial codebook using a series of steps customary to qualitative research to reinforce reliability and consistency between coders (Strauss \& Corbin, 1998). Two independent coders reviewed the transcripts, and extracted participant commentary relevant to policymakers across six domains: (1) objectification of the female body, (2) depictions of women in media, (3) mental health stigma, (4) health care practice and access, (5) education, and (6) insurance reform. These domains were chosen given prior work on ED etiology and recovery, and salient themes that persisted across the sample. The first author and a graduate research assistant then coded six random transcripts, and met to discuss the codes and assess reliability $(\kappa=.78)$. To assure continued reliability, the first author coded all thirty transcripts, and the graduate research assistant also coded seven randomly selected interviews $(\kappa=.84)$. At both junctures, discrepancies among codes were resolved by a third random coder, another graduate research assistant.

\section{Results}

In response to the guiding prompt, participants shared a total of 304 photographs $(M=10.13, S D=5.56)$, and offered 82 suggestions (range $1-11, M=2.82, S D=2.07)$ across the 30 interviews. These suggestions fell into six categories or themes: media ( $n=$ 
18), healthcare practice and access $(n=18)$, insurance reform $(n=14)$, education $(n=$ 13), objectification of the female body $(n=12)$, and mental health stigma $(n=7)$. Each of these themes is expanded upon below, with key participant examples, and appear with relevant sub-themes in Tables 4-8, with the exception of mental health stigma, which was not comprised of additional sub-themes.

\section{Media}

Unsurprisingly, nearly all (90\%) of participants noted the role media and social media and the sociocultural pressures from the general media played in their disorder and the ways in which these messages both help and hinder their recovery process. Thirteen of those participants had specific suggestions for the curation and regulation of images and diet information from both the media and social media. Participants supported a reduction in the number of depictions of underweight women in advertisements, television, movies, and across photo-based social media platforms, such as Instagram. Social media, websites, commercials, and magazines were also mentioned as conduits of information promoting disordered eating behavior that was supremely unhelpful during the ED recovery process. According to Caroline (age 19):

It should be regulated more, it shouldn't be so...maybe it's not even up to the government, but they should regulate more what we're all exposed to...because, you know you go anywhere and all you see are these molds, these perfect molds that we're pushed to fit. I think that it should be regulated and there should be a certain limit...not everything should be about how to lose weight and how to, you know, how to get smaller. Also on the Internet there's so much that should be taken down. All these tips and tricks and how to you know starve yourself and how to purge and how to do this and that... 
I think it was American Eagle that they had like their Aerie bathing suits... That they're like not retouching the models... that helps a lot, definitely...

I would have them [fat women] not in

Increased diversity in tv/movies

\section{Media} token roles. I would have them as main characters doing serious stuff as well as... yeah I just think they need to increase body diversity on $t v$.

I'm not gonna be able to pull off certain Fashion designed for bodies of all sizes $(n=4)$

Decreased body shaming $(\mathrm{n}=3)$ fashions ever. It's okay, and I'm learning that but it's really painful when the only examples you ever see are like boxes you'll never fit in

I don't think its ok to fat shame, I don't think its ok to skinny shame, I don't think its ok to shame anyone for whatever they look like

Table 4. Media sub-themes

\section{Healthcare Practice and Access}

The area most frequently mentioned as an avenue for policy change was healthcare practice and access. Thirteen participants (43\%) offered four unique areas of improvement healthcare access and practice for women in ED recovery: more thorough training for doctors, improved treatment of co-morbid physical health issues, less of an emphasis on weight and BMI, and greater access to competent care. Nearly a quarter of the sample $(n=7)$ noted the lack of education medical doctors receive on diagnosing and treating eating disorders, or spotting co-morbid psychological and medical conditions. The two participants in the sample who had experienced pregnancy highlighted the importance of receiving specialized pre- and post-natal care informed by ED treatment 
specialists. Furthermore, participants noted the lack of sensitive and empathic discourse they received from medical providers about eating and weight concerns. According to

Steph (age 31):

I think that it says that our doctors are being trained wrong. I have heard numerous stories from friends across the board of insensitive doctors in a wide variety of like areas, not just like PCP not just like... and they, they, they're not trained. They don't know how to talk about body weight. I've had one friend uh, shamed by her gynecologist, yeah... And I think in a field especially like endocrinology you can't just tell people they're fat and that's why they have problems... (They need) training for the doctors... that would be more sensitive about language and I would actually get them nutrition information that is accurate instead of just what the U.S. government says....

$\begin{array}{cl}\begin{array}{c}\text { More thorough } \\ \text { training for doctors } \\ (\mathrm{n}=8)\end{array} & \begin{array}{l}\text { I think that it says that our doctors } \\ \text { are being trained wrong...they, } \\ \text { they're not trained. They don't know } \\ \text { how to talk about body weight. }\end{array} \\ \begin{array}{c}\text { Improved treatment } \\ \text { of co-morbid } \\ \text { physical health issues } \\ (\mathrm{n}=6)\end{array} & \begin{array}{l}\text { I know that losing weight will solve a the [diabetes] problems but, it } \\ \text { might not, it might just backfire }\end{array} \\ \begin{array}{c}\text { Less of know, I'm 5'6" and then they } \\ \text { on weight and BMI } \\ (\mathrm{n}=5)\end{array} & \begin{array}{l}\text { weigh me and technically, I'm over } \\ \text { the weight limit of my height range } \\ \text { and my body mass index should be. } \\ \text { But I'm not fat, I'm not unhealthy, it's } \\ \text { just muscle. And they, sometimes the } \\ \text { make you feel that you're overweight } \\ \text { or you don't fit into those sort of } \\ \text { borderline guidelines that they have. }\end{array} \\ \begin{array}{c}\text { More treatment } \\ \text { options and resources } \\ (\mathrm{n}=4)\end{array} & \begin{array}{l}\text { I guess it would help to have more } \\ \text { support groups, art therapy, things } \\ \text { like that, that are more therapeutic } \\ \text { and easy to access. }\end{array}\end{array}$

Table 5. Healthcare practice and access sub-themes 
Relatedly, participants spoke with frustration about lack of access to mental and physical healthcare in the United States, as it can be especially cost-prohibitive and the requirements for admission into intensive treatment can be extreme. More than one participant noted that when she began seeking treatment, she was told her BMI was not low enough to warrant care, or her electrolyte values were not abnormal enough. For example, Ber (age 32) noted:

and I wasn't 'anorexic' at the time because I would eat but I would just throw up and I wasn't underweight so I was eating nonetheless so I didn't have an actual diagnosis, I checked what my BMI was. (I was) on the brink of death and I had to fight them like do you know how devastating it is when you're finally willing to get the help and then you have to actually have to prove that, like you have doctors telling you, no you're not sick enough....like, do you know how messed up that is? So like, tell someone who's trying to get sicker that they're not sick enough, and it causes selfsabotage.

\section{Health Insurance Reform}

Over one-third ( $n=12)$ of participants mentioned the need for insurance and healthcare reform at the national level, to ensure that individuals receive the mental and physical healthcare they need, as it is often out of reach for low and middle-income U.S. families. Participants expressed frustration at both insurance corporations and politicians for regularly failing to meet the needs of this population. One participant (Jen, 23) remembered the financial drain her recovery placed on her family's resources:

A lot of insurances don't see this as medical situation, they don't cover fully the treatments, they might cover psychiatrist and medication but at this point there's not a lot of medication you can take maybe something for the anxiety. But I do remember having to stop treatments because I couldn't pay for it when I was around maybe $15 \ldots$ at the time, if I remember correctly, there used to be these powdered mixes that had a lot of calories, a lot of protein, I want to say they were called like the (shake name). They tasted really gross but insurance wouldn't cover that because 
they consider it a health shake, protein shake. And those were very expensive, it was like $\$ 60$ for a box, maybe like a week's supply. We've always had a very low income, my grandmother never worked in this country and my grandfather had minimum wage his whole life, since we've been here. So it was difficult to afford that kind of treatment.

\section{Health Insurance Reform}

I mean that [cost] kept me the

Affordability of treatment $(\mathrm{n}=9)$

Insurance stopping coverage prematurely

$$
(\mathrm{n}=5)
$$

longest from ever reaching out cause how can you drop that much money as a college student? ..insurance has no right to all of a sudden say oh you ate three meals a day for seven days in a row you must be fine.

\section{Table 6. Healthcare insurance reform sub-themes}

Em (age 23) reflected on how detrimental the 2017 Republican-backed Healthcare reform bill would be for women in general, particularly those recovering from clinical EDs:

I want to feel like politicians are actually working hard to help us...Instead of you know, taking away like, I mean I can list so many things actually... but, you know, the big thing is taking away like our um... access to basic health care for example I think that's an important things because if, if I had been this age when I developed an eating disorder I wouldn't have been able to afford treatment um...so it's kind of like "help us, don't make us...don't villainize us" and we're not...this isn't something that we do out of vanity. It's more like, we can't help it, it's a disorder, you know, just like I can't help that you know I'm depressed or that I have anxiety.

\section{Education}

Over one-third $(n=12)$ participants highlighted the need for more education around EDs, both to prevent their development and also to help 
parents, friends, and family members support individuals through the recovery

process.

\begin{tabular}{|c|c|c|}
\hline \multirow[t]{3}{*}{ Education } & $\begin{array}{c}\text { Education for } \\
\text { young girls } \\
\quad(n=11)\end{array}$ & $\begin{array}{l}\text {...maybe there should be like a } \\
\text { class like early on before college. } \\
\text { Maybe in middle school like of to } \\
\text { bring awareness of like the girls } \\
\text { and um really um incorporate body } \\
\text { positivity }\end{array}$ \\
\hline & $\begin{array}{l}\text { Education for } \\
\text { medical providers } \\
\quad(n=8)\end{array}$ & $\begin{array}{l}\text { I wish they [doctors] were more } \\
\text { empathetic. More, like, that they } \\
\text { would kind of educate themselves of } \\
\text { the mind of someone going through } \\
\text { an eating disorder }\end{array}$ \\
\hline & $\begin{array}{l}\text { Education for } \\
\text { families } \\
\quad(\mathrm{n}=3)\end{array}$ & $\begin{array}{l}\text {...it's just not part of the culture so } \\
\text { like, I don't expect them [family] to } \\
\text { understand everything overnight } \\
\text { and like how psychology and all } \\
\text { this stuff works together but, I } \\
\text { mean, I wish it would be... there } \\
\text { would be more like, education on it }\end{array}$ \\
\hline
\end{tabular}

Table 7. Education sub-themes

Participants saw the benefit of teaching intuitive eating and dietary

flexibility at a young age, educating adolescents on the detrimental effects of social media use and the realities of the fashion and performing industries, and educational programs to improve self-esteem, self-efficacy, and self-worth in children and adolescents. Anastasia (age 21) reflected:

A lot of times I think that when people go into an eating disorder, they just don't...they're not educated enough. Well obviously they're not educated about food or anything... it has to be implemented in like the families have to get educated on how to see those things and how to prevent those things because for me no one knew like....I guess it has to be education in the for parents. Mostly for parents. First place. So that they can see it and watch it and like have an idea of that that can happen. I don't think my parents had 
any idea that that could have happened. So definitely that, and I feel like that's one of the few things that can be done in this situation.

\section{Objectification of the Female Body}

Nearly one-third $(n=9)$ of participants thought it prudent to improve upon the way society views the female body, primarily as an object that needs to be pleasant to look at and fit unrealistic beauty ideals. Participants who had been pregnant $(n=2)$ spoke of the unique objectifying statements they received during their pregnancies. Furthermore, participants discussed the use of beauty as currency in our current culture, and the overarching belief that this message extends beyond looks to merely having permission to exist - that women are not supposed to take up physical, emotional, or intellectual space. As put by Kate (age 20):

You have to be thin if you are perfect. And you have to be perfect if you are a woman. It's like the price you pay to exist in this world as a woman. I read that somewhere. I didn't come up with that. The rent you pay is by being pretty and perfect... I'm not sure why we are this way, but we have put this requirement on women that unless you are a certain body type, you do not belong, especially in the United States..... we have decided that for some reason that women have to look a certain way and if you look anything different then that certain way, then you are wrong and you don't actually deserve to exist in this world and that's not very fair. 


\section{Objectification of the Female Body}

Decreases in the use of women's bodies to sell products $(n=4)$

...putting restrictions on certain like advertisements and things like that. Like there's a commercial that I hate...I wish there was a restriction where it would be like if you you know...Just stop. Like no more portrayal of sexualized females anymore in any media anything like that

...if you are pretty, then the men can take advantage of you and then you'll get parts

Shifts in the idea of using beauty as

$$
\text { currency } \quad(n=3)
$$

because they took advantage of you and as long as your quiet, you'll keep getting good [jobs] so I think that's probably why pretty girls succeed, pretty thin girls

I think the big cultural message that everything boils

Giving women more permission to take up space in society \& male-dominated fields

$$
(n=3)
$$

down to is that women are not supposed to take up space. And that's the thing I am fixating on. How much space am I taking up, and is it more space than I'm allowed?

Table 8. Objectification of the female body sub-themes

\section{Mental Health Stigma}

Nearly one-quarter of participants $(n=6)$ offered recommendations

for decreasing mental health stigma and increasing empathy for those suffering from EDs at the individual and societal level. Several participants noted the helpfulness of medical marijuana in overcoming their EDs, and wished the legalization of marijuana was a less polarizing topic. Nearly 
every time a participant mentioned mental health stigma, it was made clear that the stigmatized societal attitude extended beyond eating disorders to general mental health. Ali (age 35) said,

It needs to be a less taboo subject. And it needs to be taken more seriously. Because I feel like so many people just think it's this vain disease, that it's, you know, nobody understands how much deeper it goes, unless they've been there. Um, and there's so much... it's not just the eating disorder, it's mental health in general, there's such a negative stigma that like, nobody talks about it. And it just makes those dealing with it that much less likely to seek help, feel that much more alone, and that needs to change.

\section{Discussion}

Using the PhotoVoice method, the current study identified areas for potential policy and healthcare reform, informed by recommendations of a diverse group of women in ED recovery. Six themes related to ED policies and practices emerged: changes to mass and social media, healthcare practice and access, health insurance reform, education, objectification of the female body, and mental health stigma. Contributors' frustrations and suggestions for improvement echoed those from professional organizations specializing in the treatment of eating disorders (Puhl, Neumark-Sztainer, Austin, Luedicke, \& King, 2014). For example, both highlight inadequate access to quality care (Kazdin et al., 2017), and the research-practice gap (Schoenwald, McHugh, \& Barlow, 2012), as women continue to be affected by robust sociocultural factors identified in the scientific literature, such as objectification (Grabe, Ward, \& Hyde, 2008), and these sociocultural factors result in the perpetuation of unachievable cultural norms, such as the thin-ideal. Thus, findings from the present study underscore opportunities for change action at the policy and societal level to support larger-scale impact (Austin, 2015). 


\section{Opportunities for reform}

Mass and social media. The most frequently mentioned avenues for reform were mass and social media outlets. Both have been frequently implicated as causal and correlational factors for increases in body dissatisfaction and disordered eating (Mabe, Forney, \& Keel, 2014; Saunders \& Eaton, in press). Many participants were familiar with the recent law in France banning models with low body mass indices $(<18)$ and warning labels indicating an image had been altered (Wissinger, 2015). While providing a warning label has not proved efficacious in experimental settings (Bury, Tiggemann, \& Slater, 2016), body diversity in advertising and images holds the potential to decrease body dissatisfaction, for instance, for individuals with a greater tendency to engage in appearance-related social comparisons, or for whom the body does not conform to the thin ideal (Convertino, Rodgers, Franko, \& Jodoin, 2016). Also successful in improving body image, and thus reducing the risk of disordered eating, is a focus on body function over appearance (Paraskeva, Lewis-Smith, \& Diedrichs, 2017).

Given these prior findings, one suggestion emerging from the PhotoV oice project concerning social and mass media would be to place a similar restriction on the size of models portrayed in the fashion industry and advertisers, and instead, feature women representing a wide diversity of shapes, colors, and sizes. More women in positions of power within the media structure would aid in promoting this change. The current and prior findings also highlight the need for more thoughtful and educated consumers. Programs to promote mass and social media literacy for consumers at a very young age (such as that designed by Bird and colleagues, 2013) would assist young girls in accurately processing the images they are inundated with from a young age (Dohnt \& 
Tiggemann, 2006). Lastly, the media could be leveraged to inspire healthy communication about sociocultural risk factors, health disparities in access to care, and disordered eating. For instance, communication about health disparities delivered through mass media channels has resulted in increased support for policies to bolster social determinants of well-being within disenfranchised groups (Niederdeppe, Bigman, Gonzales, \& Gollust, 2013). The same may be true regarding communication of the role mass and social media have on disordered eating outcomes.

Objectification of women. As illustrated by both the photographs and accompanying narratives, this systemic change at the societal and cultural level may have cascading influences on not only the way women's bodies are portrayed and talked about, but also by challenging the patriarchal system that promotes sexual objectification and third-person perspective of women's bodies (Calogero \& Tylka, 2014). Many participants spoke of beauty and body as a currency for success in the modern world, highlighting a larger societal issue that extends beyond disordered eating. Objectification theory (Fredrickson \& Roberts, 1997) presumes that gender roles and sexual objectification practices promulgated by society lead women to subsume an external self-perspective, disregarding internal attributes and sensations and instead placing excessive focus on appearance and misguided attempts to achieve society's beauty standards.

Self-objectification has cascading consequences on women's mental health outcomes including but not limited to EDs. While popular media propagates the misconception that EDs are rooted in vanity and narcissism, objectification theory offers an alternative interpretation: women assimilate to an observer-oriented self-perception not out of self-absorption, but as an anticipatory strategy that allows for a modicum of 
agency in how one will be regarded by others (Calogero, Tantleff-Dunn, \& Thompson, 2011). The current findings support this interpretation and provide insight into how a subset of women, whether consciously or subconsciously, successfully challenge the system that promotes self-objectification and ongoing gender inequality. Participants explicitly mentioned the role of the patriarchy in maintaining an unrealistic and dehumanizing view of the female body, and how this view is made evident to girls from a very young age and pervades multiple societal domains.

Healthcare practice and access. When asked directly if they had advice to offer policymakers and the government, the vast majority of participants offered areas of improvement in health care practice and access, followed closely by the need for health insurance reform. This is especially relevant as impending healthcare reform policies in the United States (i.e., repeal of the Affordable Care Act) have the potential to curtail access to necessary treatment (American Psychological Association, 2016) for individuals suffering from physical and mental illness, including clinical eating disorders. Prior experimental research has indicated that both the general public and ED treatment professionals agree there is need for more training for educators and doctors, to enable the early identification of disordered eating behavior and subsequent appropriate referrals to specialists (Puhl et al., 2014). Several participants expressed anger and frustration over the seemingly negligent and weight-stigmatized care they received from non-specialists, sharing that such interactions hindered, rather than promoted, their recovery trajectory. Few individuals with clinical EDs seek medical or psychiatric care explicitly for their eating and/or weight disorder (Williams, Goodie, Motsinger, 2008); hence, the current 
finding reiterates the need for better medical and psychosocial training for providers most likely to interact with patients who may be suffering from an ED.

Healthcare reform. Furthermore, while more recent legislative changes have achieved parity for mental illness to be recognized and treated similar to a physical illness, the criteria for coverage remain quite conservative (Hewitt, 2013), preventing individuals with clinical EDs from receiving the intensity and duration of care that is clinically recommended. Many participants shared details of their exasperating personal experience with this loophole in insurance coverage. These experiences are not unique to the current sample; the National Eating Disorders Association (NEDA) has issued a statement highlighting the most common reasons for denial of coverage (NEDA, 2018), which include paradoxical rationales: weight not low enough, condition is either considered chronic or improved slightly without care, or lack of severe medical complications. Legislation aiming to improve access to care for individuals in ED recovery has been introduced and signed, and will hopefully serve as an important step in increased access to care for individuals in need.

Education and stigma reduction. Along with educating medical providers, participants spoke of the importance of educating children at a young age to be attuned to their bodies and cultivate body appreciation. Many women noted that yoga had supported their recovery process, which is further supported by prior research incorporating mindfulness and self-care into ED treatment (Cook-Cottone, 2015). The frequency with which education was highlighted as an avenue for reform suggests that existing education programs in secondary and university settings may be insufficient to mitigate risk for EDs. Education programs tailored to parents of adolescents have been met with success 
(Lock \& le Grange, 2005), and based on feedback from our participants, we suggest expanding such programs to peers and other close-knit social ties.

However, prior research indicates such education needs to be delivered in a sensitive and intentional manner, as ED public service announcements have had the unintended consequences of increasing negative attitudes toward individuals with EDs (Iles, Seate, \& Waks, 2017). This stigmatization was also acknowledged by participants, and challenging mental health stigma emerged as another salient theme with implications for policymaking and intervention. Stigma towards individuals with EDs is frequent and well documented (Puhl et al., 2014; Roehig \& McLean, 2010), and associated with multiple adverse outcomes (Griffiths, Mond, Murray, \& Touyz, 2015). Simultaneously targeting education and stigmatization will be important in maximizing the effects of any attempts at systematic change. Ideally, efforts to improve education and reduce stigma could be efficient and synergistic, i.e., as the public (providers, families, etc.) become better informed, stigma may also decrease. Thus, interventions with an eye toward both could maximize efficiency and efficacy.

\section{Conclusion}

Women in ED recovery highlighted six key areas of reform that they viewed as supportive of the ED recovery process. Existing agencies and opportunities, such as the Eating Disorder Coalition National Lobby Days on Capitol Hill, and annual awareness campaigns by NEDA are two mechanisms for these findings to hold influence. The current findings emphasize the importance of pushing existing legislation and reform forward, as the progress made at the national level needs to be maintained and expanded to ensure the availability and affordability of competent care for more individuals 
suffering from this debilitating disorder. The National Institute of Mental Health has an ED research program within the Division of Translational Research, aiming to use research to improve treatment outcomes, and the points raised by women in ED recovery underscore that this funding is sorely needed. In the words of one participant, we need to take more steps to fix this "disordered society." 


\section{CONCLUSION}

Through a series of four successive and interlocking mixed-methodological studies, the current dissertation draws from social comparison theory (Festinger, 1954; Suis \& Wheeler, 2000) and objectification theory (Fredrickson \& Roberts, 1997; Moraldi \& Varnes, 2017), guided by the overarching meta-theory of RDST (Overton, 2013), to critically examine the function of social comparison and sexual objectification during ED recovery. The studies contained within highlight both the ways in which an individual and her context can together both shape a dysfunctional and potentially deadly relationship with food, and also promote positive developmental outcomes when viewed from a shifted perspective and with different motives.

In taking a mixed-methodological approach to examining body-, eating-, and exercise-related comparisons during the ED recovery process, this dissertation underscores the important changes that occur in social comparison processes to promote and sustain recovery. While the antecedents of thin ideal internalization have not been solidified in the literature, likely because it emerges incredibly early for young girls, potentially by age four (Brown \& Slaughter, 2011), there are dozens of published models linking thin ideal internalization to body dissatisfaction, with multiple sociocultural-based mediators, namely social comparison and self-objectification. These models, and the one featured in Study Three, build off of the initial Tripartite Influence Model (Keery et al., 2004). The Tripartite Influence Model was initially fit to data from adolescent girls. In time, instead of directly linking the environmental feedback to body dissatisfaction by way of social comparison, newer models and the one in Study Three consider social comparison as a mediator of the relationship between thin ideal internalization and body 
dissatisfaction. This mediating construct is often considered to be a typical developmental milestone or phase. To one degree or another, all young girls and women will engage in social comparisons as a normative developmental process (Harter, 2006). Rodgers, McLean, and Paxton (2015) conducted a longitudinal study to tease apart the causal relationship between thin ideal internalization, appearance-related social comparison, and body dissatisfaction, and found that they occurred in the above order in a sample of early adolescent girls. Greater levels of thin ideal internalization were predictive of higher levels of appearance-related social comparison, which then predicted higher levels of body dissatisfaction.

The current findings demonstrate how, during ED recovery, these same comparisons can serve to bolster and solidify one's recovery trajectory if engaged in from a recovery promoting perspective (Study 1). The form these comparisons take differs during ED recovery in contrast to the form they take prior to the development of clinically significant eating pathology. The factor structure for the one existing measure of body-, eating-, and exercise-related comparisons (Fitzsimmons-Craft et al., 2012) does not replicate for our recovery sample, and instead the data fit a model well after the removal of three items related to eating and one related to body comparisons (Study 2). The removed items relate to specific comparisons that become less functional during recovery.

Following the development of a clinically significant ED, social comparison tendencies change, as do the interrelations among thin-ideal internalization, social comparison, body dissatisfaction \& disordered eating. The relations within the sociocultural model of disordered eating, specifically the link between thin-ideal 
internalization and social comparison, weaken for women with active EDs, and are no longer statistically significant for women in recovery (Study 3). These findings, as well as the suggestions garnered from the same interviews used in Study 1, when re-examined to extract suggestions for clinicians and policymakers, have the potential to shape future prevention, treatment, societal, and cultural guidelines. Women in recovery offered suggestions falling into six broad themes: media, healthcare practice and access, health insurance reform, education, objectification of the female body, and mental health stigma. These suggestions will be disseminated to the scientific community through publication, and with policymakers and the public through a PhotoVoice exhibit that will travel to an Eating Disorder Coalition Lobby Day on Capitol Hill.

The current dissertation allowed women to tell the story of their recovery process through photographs and semi-structured interviews, and these stories were examined further through quantitative approaches. Given the tight interrelations among the environment, internalization of the thin-ideal, and appearance-related social comparisons as contributors to disordered eating outcomes, the studies within this dissertation accentuate the bi-directional, reciprocal relationship an individual and her context have in promoting both disordered eating and recovery, a bi-directionality that is essential to the study of developmental science and often absent when a more clinically-driven lens is applied to eating pathology. 


\section{REFERENCES}

Allen, K. L., Byrne, S. M., Oddy, W. H., \& Crosby, R. D. (2013). DSM-IV-TR and DSM-5 eating disorders in adolescents: Prevalence, stability, and psychosocial correlates in a population-based sample of male and female adolescents. Journal of Abnormal Psychology, 122(3), 720-732. doi:10.1037/a0034004

Arigo, D., Schumacher, L., \& Martin, L. M. (2014). Upward appearance comparison and the development of eating pathology in college women. International Journal of Eating Disorders, 47(5), 467-470. doi: 10.1002/eat.22240

Arnett, J. J. (2000). Emerging adulthood: A theory of development from the late teens through the twenties. American Psychologist, 55(5), 469-480. doi: 10.1037/0003-066X.55.5.469

Austin, S. B. (2016). Accelerating progress in eating disorders prevention: a call for policy translation research and training, Eating Disorders, 24(1), 6-19. doi: 10.1080/10640266.2015.1034056

Baltes, P. B., Reese, H. W., \& Nesselroade, J. R. (1977). Life-span developmental psychology: Introduction to research methods. Erlbaum: Hillsdale, NJ.

Bardone-Cone, A. M., Harney, M. B., Maldonado, C. R., Lawson, M. A., Robinson, D. P., Smith, R., \& Tosh, A. (2009). Defining recovery from an eating disorder: Conceptualization, validation, and examination of psychosocial functioning and psychiatric comorbidity. Behaviour Research and Therapy, 48(3), 194-202. doi: 10.1016/j.brat.2009.11.001

Bardone-Cone, A. M., Schaefer, L. M., Maldonado, C. R., Fitzsimmons, E., Harney, M. B. (2010). Aspects of self-concept and eating disorder recovery: What does the sense of self look like when an individual recovers from an eating disorder? Journal of Social and Clinical Psychology, 29(7), 821-846. doi: $101521 /$ jscp.2010.29.7.821

Bardone-Cone, A. M., Sturm, K., Lawson, M. A., Robinson, D. P., \& Smith, R. Perfectionism across stages of recovery from eating disorders. International Journal of Eating Disorders, 43(2), 139-148. doi: 10.1002/eat.20674

Bird, E., Halliwell, E., Diedrichs, P. C., \& Harcourt, D. (2013). Happy being me in the UK: A controlled evaluation of a school-based body image intervention with preadolescent children. Body Image, 10(3), 326-334. doi: 10.1016/j.bodyim.2013.02.008 
Braver, S. L., \& Bay, R. C. (1992). Assessing and compensating for self-selection bias (nonrepresentativeness) of the family research sample. Journal of Marriage and the Family, 54, 925-939. doi:10.2307/353173

Braun, V., \& Clarke, V. (2006). Using thematic analysis in psychology. Qualitative Research in Psychology, 3(2), 77-101. doi: 10.1191/1478088706qp063oa

Breithaupt, L., Eickman, L., Byrne, C. E., \& Fischer, S. (2017). Enhancing empowerment in eating disorder prevention: Another examination of the Rebel peer education model. Eating Behaviors, 25, 38-41. doi: 10.106/j.eatbeh.2016.05.003.

Brown, F.L., \& Slaughter, V. Normal body, beautiful body: Discrepant perceptions reveal a pervasive 'thin ideal from childhood to adulthood. Body Image, 8(2). 119-125. doi: 10.1016/j.bodyim.2011.02.002

Brown, Z., \& Tiggemann, M. (2016). Attractive celebrity and peer images on Instagram: Effect on women's mood and body image. Body Image, 19, 37-43. doi:10.1016/j.bodyim.2016.08.007

Brunsden, V., \& Goatcher, J. (2007). Reconfiguring photovoice for psychological research. The Irish Journal of Psychology, 28(1-2), 43-52. doi:10.1080/03033910.2007.10446247

Bury, B., Tiggemann, M., \& Slater, A. (2016). Disclaimer labels on fashion magazine advertisements: Impact on visual attention and relationship with body dissatisfaction. Body Image, 16, 1-9. doi: 10.1016/j.bodyim.2015.09.005

Calogero, R. M. (2013). Objects don't object: evidence that self-objectification disrupts women's social activism. Psychological Science, 24(3), 312-318. doi: $10.1177 / 0956797612452574$

Calogero, R. M., Davis, W. N., \& Thompson, J. K. (2005). The role of selfobjectification in the experience of women with eating disorders. Sex Roles, 52(12), 43-50. doi:10.1007/s11199-005-1192-9

Calogero, R. M., Tantleff-Dunn, S. E., \& Thompson, J. (2011). Objectification theory: An introduction. In R. M. Calogero, S. E. Tantleff-Dunn, \& J. Thompson (Eds.). Self-objectification in women: Causes, consequences, and counteractions (pp. 321). Washington, DC: American Psychological Association.

Calogero, R. M., \& Tylka, T. L. (2014). Sanctioning resistance to sexual objectification: An integrative system justification perspective. Journal of Social Issues, 70(4), 763-778. doi: 10.1111/josi.12090 
Capodilupo, C. M. (2015). One size does not fit all: Using variables other than the thin ideal to understand Black women's body image. Cultural Diversity and Ethnic Minority Psychology, 21 (2), 266-278. doi: 10.137/a0037649

Convertino, A. D., Rodgers, R. F., Franko, D. L., \& Jodoin, A. (2016, e-pub ahead of print) An evaluation of the Aerie Real campaign: Potential for promoting positive body image? Journal of Health Psychology, 1-12. doi:

$10.1177 / 1359105316680022$

Cook-Cottone, C. P. (2015). Incorporating positive body image into the treatment of eating disorders: A model for attunement and mindful self-care. Body Image, 14, 158-167. doi:10.1016/j.bodyim.2015.03.004

Cornwall, A., \& Jewkes, R. (1995). What is participatory research?. Social Science \& Medicine, 41(12), 1667-1676. doi: 10.1016/0277-9536(95)00127-S

Culbert, K. M., Racine, S. E., \& Klump, K. L. (2015). Research Review: What we have learned about the causes of eating disorders-a synthesis of sociocultural, psychological, and biological research. Journal of Child Psychology and Psychiatry, 56(11), 1141-1164. doi: 10.1111/jcpp.12441

Darcy, A. M., Katz, S., Fitzpatrick, K. K., Forsberg, S., Utzinger, L., \& Lock, L. (2010). All better? How former anorexia nervosa patients define recovery and engaged in treatment. European Eating Disorders Review, 18, 260-270. doi: 10.1002/erv. 1020

De Vos, J. A., LaMarre, A., Radstaak, M., Bijkerk, C. A., Bohlmeijer, E. T., \& Westerhof, G. J. (2017). Identifying fundamental criteria for eating disorder recovery: a systematic review and qualitative meta-analysis. Journal of Eating Disorders, 5, 34. doi:10.1186/s40337-017-0164-0

Dohnt, H., \& Tiggemann, M. (2006). The contribution of peer and media influences to the development of body satisfaction and self-esteem in young girls: A prospective study. Developmental Psychology, 42(5), 929-936. 10.1037/00121649.42.5.929

Enders, C. K. (2003). Using the expectation maximization algorithm to estimate coefficient alpha for scales with item-level missing data. Psychological Methods, 8(3), 322-337. doi: 10.1037/1082-989X.8.3.322

Fairburn, C. G., \& Beglin, S. J. (2008). Eating Disorder Examination Questionnaire (EDE-Q 6.0). In C. G. Fairburn (Ed.), Cognitive behavior therapy and eating disorders (pp. 309-313). New York: Guilford Press. 
Festinger, L. (1954). A theory of social comparison processes. Human Relations, 7(2), 117-140. doi: 10.1177/001872675400700202

Fitzsimmons-Craft, E. E. (2017). Eating disorder-related social comparison in college women's everyday lives. International Journal of Eating Disorders, 50(8), 893905. doi: 10.1002/eat.22725

Fitzsimmons-Craft, E. E. (2011). Social psychological theories of disordered eating in college women: Review and integration. Clinical Psychology Review, 31(7), 1224-1237. doi: 10.1016/j.cpr.2011.07.011

Fitzsimmons-Craft, E. E., \& Bardone-Cone, A. M. (2014). One-year temporal stability and predictive and incremental validity of the Body, Eating, and Exercise Comparison Orientation Measure (BEECOM) among college women. Body Image, 11(1), 27-35. doi: 10.1016/j.bodyim.2013.09.003

Fitzsimmons-Craft, E. E., Bardone-Cone, A. M., Bulik, C. M., Wonderlich, S. A., Crosby, R. D., \& Engel, S. G. (2014). Examining an elaborated sociocultural model of disordered eating among college women: The roles of social comparison and body surveillance. Body Image, 11(4), 488-500. doi: 0.1016/j.bodyim.2014.07.012

Fitzsimmons-Craft, E. E., Bardone-Cone, A. M., Crosby, R. D., Engel, S. G., Wonderlich, S. A., \& Bulik, C. M. (2016). Mediators of the relationship between thin-ideal internalization and body dissatisfaction in the natural environment. Body Image, 18, 113-122. doi: 10.1016/j.bodyim.2016.06.006

Fitzsimmons-Craft, E. E., Bardone-Cone, A. M., \& Harney, M. B. (2012). Development and validation of the Body, Eating, and Exercise Comparison Orientation Measure (BEECOM) among college women. Body Image, 9(4), 476-487. doi: 10.1016/j.bodyim.2012.07.007

Fitzsimmons-Craft, E. E., Bardone-Cone, A. M., \& Kelly, K. A. (2011). Objectified body consciousness in relation to recovery from an eating disorder. Eating Behaviors, 12(4), 302-308. doi: 10.1016/j.eatbeh.2011.09.001

Fitzsimmons-Craft, E. E., Ciao, A. C., \& Accurso, E. C. (2016). A naturalistic examination of social comparisons and disordered eating thoughts, urges, and behaviors in college women. International Journal of Eating Disorders, 49(2), 141-150. doi:10.1002/eat.22486

Foster-Fishman, P., Nowell, B., Deacon, Z., Nievar, M. N., \& McCann, P. (2005). Using methods that matter: The impact of reflection, dialogue, and voice. American Journal of Community Psychology, 36, 275-291. doi: 10.1007/s10464-005-8626-y 
Frank, L., Basch, E., \& Selby, J. V. (2014). THE PCORI perspective on patient-centered outcomes research. JAMA, 312(15), 1513-1514. doi:10.1001/jama.2014.11100

Frederick, D. A., Daniels, E. A., Bates, M. E., \& Tylka, T. L. (2017). Exposure to thinideal media affect most, but not all women: Results from the Perceived Effects of Media Exposure Scale and open-ended responses. Body Image, 23, 188-205. doi: 10.1016/j.bodyim.2017.10.006

Fredrickson, B. L., \& Roberts, T. A. (1997). Objectification theory. Psychology of Women Quarterly, 21(2), 173-206.

Gibbons, F. X., \& Buunk, B. P. (1999). Individual differences in social comparison: Development of a scale of social comparison orientation. Journal of Personality and Social Psychology, 76(1), 129-142. doi:10.1037/0022-3514.76.1.129

Grabe, S., Ward, L. M., \& Hyde, J. S. (2008). The role of the media in body image concerns among women: A meta-analysis of experimental and correlational studies. Psychological Bulletin, 134(3), 460-476. doi:10.1037/00332909.134.3.460

Gregertsen, E. C., Serpell, L., \& Mandy, W. (2017). The Egosyntonic Nature of Anorexia: An Impediment to Recovery in Anorexia Nervosa Treatment. Frontiers in Psychology, 8, (2273), 1-9.

Griffiths, S., Mond, J.M., Murray, S.B., \& Touyz, S. (2015) The prevalence and adverse associations of stigmatization in people with eating disorders. International Journal of Eating Disorders, 48(6), 767-774. doi: 10.1002/eat.22353

Han, C. S., \& Oliffe, J. L. (2016). Photovoice in mental illness research: A review and recommendations. Health: An Interdisciplinary Journal for the Social Study of Health, Illness, and Medicine, 20(2), 110-126. doi: 10.1177/1363459314567790

Hart, L. M., Granillo, M. T., Jorm, A. F., \& Paxton, S. J. (2011). Unmet need for treatment in the eating disorders: A systematic review of eating disorder specific treatment seeking among community samples. Clinical Psychology Review, 31(5), 727-735. doi: 10.1016/j.cpr.2011.03.004

Harter, S. (2006). The self. In W. Damon \& R. M. Lerner (Eds.), Handbook of child psychology (pp. 505-570). Hoboken, NJ: John Wiley \& Sons, Inc.

Harvey, A. G., \& Gumport, N. B. (2015). Evidence-based psychologicaltreatments for mental disorders: Modifiable barriers to access andpossible solutions. Behaviour Research and Therapy, 68,1-12. doi:10.1016/j.brat.2015.02.004 
Hergenrather, K. C., Rhodes, S. D., Cowan, C. A., Bardhoshi, G., \& Pula, S. (2009). Photovoice as community-based participatory research: A qualitative review. American Journal of Health Behavior, 33(6), 686-698. doi: 10.5993/AJHB.33.6.6

Hewitt, S. (2013). A Time to Heal: Eliminating Barriers to Coverage for Patients with Eating Disorders Under the Affordable Care Act. Law and Inequality, 31, 411435.

Holland, G., \& Tiggemann, M. (2017). "Strong beats skinny every time": Disordered eating and compulsive exercise in women who post fitspiration on Instagram. International Journal of Eating Disorders, 50(1), 76-79. doi: 10.1002/eat.22559

Hu, L., \& Bentler, P. M. (1999). Cutoff criteria for fit indexes in covariance structure analysis: Conventional criteria versus new alternatives. Structural Equation Modeling: A Multidisciplinary Journal, 6(1), 1-55. doi: 10.1080/10705519909540118

IBM Corporation. (2011). IBM SPSS Statistics for Windows version 23. Armonk, NY: IBM Corp.

Iles, I. A., Seate, A. A., \& Waks, L. (2017). Stigmatizing the other: An exploratory study of unintended consequences of eating disorder public service announcements. Journal of Health Psychology, 22(1), 120-131. doi: 10.1177/1359105315595453

Ison, J. \& Kent, S. (2010). Social identity in eating disorders. European Eating Disorders Review, 18(6), 475-485. doi:10.1002/erv.1001

Jenkins, J. \& Ogden, J. (2012), Becoming 'whole' again: A qualitative study of women's views of recovering from anorexia nervosa. European Eating Disorders Review, 20, e23-e31. doi:10.1002/erv.108

Kazdin, A. E., Fitzsimmons-Craft, E. E., \& Wilfley, D. E. (2017). Addressing critical gaps in the treatment of eating disorders. International Journal of Eating Disorders, 50(3), 170-189. doi: 10.1002/eat.22670

Keel, P. K., \& Brown, T. A. (2010). Update on Course and Outcome in Eating Disorders. International Journal of Eating Disorders, 43, 195-204. doi: 10.1002/eat.20810

Keery, H., Van den Berg, P., \& Thompson, J. K. (2004). An evaluation of the Tripartite Influence Model of body dissatisfaction and eating disturbance with adolescent girls. Body Image, 1(3), 237-251. doi: 10.1016/j.bodyim.2004.03.001 
Kelly, A. C., \& Tasca, G. A. (2016). Within-persons predictors of change during eating disorders treatment: An examination of self-compassion, self-criticism, shame, and eating disorder symptoms. International Journal of Eating Disorders, 49, 716-722. doi: 10.1002/eat.22527

Kemmis, S., \& McTaggart, R. (2005). Communicative action and the public sphere. The Sage Handbook of Qualitative Research, 3, 559-603.

LaMarre, A., \& Rice, C. (2016a). Embodying critical and corporeal methodology: digital storytelling with young women in eating disorder recovery. Forum: Qualitative Social Research, 17(2). doi: 10.17169/fqs-17.2.2474.

LaMarre, A., \& Rice, C. (2016b). Normal eating is counter-cultural: embodied experiences of eating disorder recovery. Journal of Community and Applied Social Psychology, 26, 136-149. doi:10.1002/casp.2240.

Lavender, J. M., Shaw, J. A., Crosby, R. D., Feig, E. H., Mitchell, J. E., Crow, S. J., ... \& Lowe, M. R. (2015). Associations between weight suppression and dimensions of eating disorder psychopathology in a multisite sample. Journal of Psychiatric Research, 69, 87-93. doi: 10.1016/j.jpsychires.2015.07.021

Leahey, T. M., Crowther, J. H., \& Ciesla, J. A. (2011). An ecological momentary assessment of the effects of weight and shape social comparisons on women with eating pathology, high body dissatisfaction, and low body dissatisfaction. Behavior Therapy, 42(2), 197-210. doi: 10.1016/j.beth.2010.07.003

Lerner, R. M., Agans, J. P., DeSouza, L. M., \& Gasca, S. (2013). Describing, explaining, and optimizing within-individual change across the life span: A relational developmental systems perspective. Review of General Psychology, 17(2), 179183. doi: 10.1037/a0032931

Lerner, R. M., \& Schmid Callina, K. (2014). The study of character development: Towards tests of a relational developmental systems model. Human Development, 57, 322-346. doi: 10.1159/000368784.

Lerner, R. M., \& Tolan, P. H. (2016). On the qualitative transformation of developmental science: The contributions of qualitative methods. Qualitative Psychology, 3(1), 120-124. doi: 10.1037/qup0000052.

Lin, L., \& Soby, M. (2016). Appearance comparisons styles and eating disordered symptoms in women. Eating Behaviors, 23, 7-12.

doi: 10.1016/j.eatbeh.2016.06.006 
Lindner, D., Tantleff-Dunn, S., \& Jentsch, F. (2012). Social comparison and the 'circle of objectification'. Sex Roles, 67(3-4), 222-235. doi: 10.1007/s11199-012-0175-x

Linville, D., Benton, A., O’Neil, M., \& Sturm, K. (2010). Medical providers' screening, training, and intervention practices for eating disorders. Eating Disorders, 18, 110-131. doi: 10.1080/10640260903585532.

Lock, J. \& le Grange, D. (2005). Family-based treatment of eating disorders. International Journal of Eating Disorders, 37, S647-S67. doi: 10.1002/eat.20122.

Mabe, A. G., Forney, K. J. and Keel, P. K. (2014), Do you "like" my photo? Facebook use maintains eating disorder risk. International. Journal of Eating Disorders, 47, 516-523. doi:10.1002/eat.22254

MacKinnon, D. P., Lockwood, C. M., Hoffman, J. M., West, S. G., \& Sheets, V. (2002). A comparison of methods to test mediation and other intervening variable effects. Psychological Methods, 7(1), 83-104.

Martin, S. J., \& Racine, S. E. (2017). Personality traits and appearance-ideal internalization: Differential associations with body dissatisfaction and compulsive exercise. Eating Behaviors, 27, 39-44. doi: 10.1016/j.eatbeh.2017.11.001

Mittnacht, A. M., \& Bulik, C. M. (2015). Best nutritional counseling practices for the treatment of Anorexia Nervosa: A Delphi study. International Journal of Eating Disorders, 48(1), 111-122. doi: 10.1002/eat.22319

Mond, J. M. (2016). Optimizing prevention programs and maximizing public health impact are not the same thing. Eating Disorders, 24(1), 20-28. doi:10.1080/10640266.2015.1113824

Moradi, B., \& Varnes, J. R. (2017). Structure of the Objectified Body Consciousness Scale: Re-evaluated 20 years later. Sex Roles, 77 (5-6), 325-337. doi: 10.1007/s11199-016-0731-x.

Morrison, B., \& Lilford, R. (2001). How can action research apply to health services?. Qualitative Health Research, 11(4), 436-449. doi:10.1177/104973201129119235

Muthén, L. K. and Muthén, B. O. (1998-2012). Mplus User's Guide. Seventh Edition. Los Angeles, CA: Muthén \& Muthén 
Myers, T. A., \& Crowther, J. H. (2007). Sociocultural pressures, thin-ideal internalization, self-objectification, and body dissatisfaction: Could feminist beliefs be a moderating factor? Body Image, 4(3), 296-308.

doi:10.1016/j.bodyim.2007.04.001

O’Brien, K. S., Caputi, P., Minto, R., Peoples, G., Hooper, C., Kell, S., \& Sawley, E. (2009). Upward and downward physical appearance comparisons: Development of scales and examination of predictive qualities. Body Image, 6(3), 201-206. doi:10.1016/j.bodyim.2009.03.003

National Eating Disorder Association (2018). Insurance and legal issues. Retrieved February 28, 2018 from https://www.nationaleatingdisorders.org/learn/generalinformation/insurance.

Niederdeppe, J., Bigman, C. A., Gonzales, A. M., \& Gollust, S. E. (2013). Communication about health disparities in the mass media. Journal of Communication, 63, 8-39. doi: 10.1111/jcom.12003

Overton, W. F. (2013). A new paradigm for developmental science: Relationism and relational-developmental systems. Applied Developmental Science, 17(2), 94-107. doi: 10.108/10888691.2013.778717

Overton, W. F., \& Lerner, R. M. (2014). Fundamental concepts and methods in developmental science: A relational perspective. Research in Human Development, 11, 63-73. doi: 10.1080/15427609.2014.881086

Ozier, A. D., \& Henry, B. W. (2011). Position of the American Dietetic Association: Nutrition intervention in the treatment of eating disorders, Journal of the American Dietetic Association, 111(8), 1236-1241. doi: 10.1016/j.jada.2011.06.016

Paraskeva, N. Lewis-Smith, H., \& Diedrichs, P. C. (2017). Consumer opinion on social policy approaches to promoting positive body image: Airbrushed media images and disclaimer labels. Journal of Health Psychology, 22(2), 164-175. doi:10.177/1359105315597052

Peterson, C. B., Crosby, R. D., Wonderlich, S. A., Joiner, T., Crow, S. J., Mitchell, J. E., ... \& Le Grange, D. (2007). Psychometric properties of the eating disorder examination-questionnaire: Factor structure and internal consistency. International Journal of Eating Disorders, 40(4), 386-389. doi: 10.1002/eat.20373

Piran, N. (2001). Reinhabiting the body. Feminism \& Psychology, 11(2), 172-176. doi: 10.1177/0959353501011002006 
Puhl, R. M., Neumark-Sztainer, D., Austin, S. B., Luedicke, J., \& King, K. M. (2014). Setting policy priorities to address eating disorders and weight stigma: views from the field of eating disorders and the US general public. BMC Public Health, 14(1), 524-533.

Rakhovskaya, L. M., \& Warren, C. S. (2014). Ethnic identity, thin-ideal internalization, and eating pathology in ethnically diverse college women. Body Image, 11, 438445. doi:10.106/j.bodyim.2014.07.003

Rancourt, D., Schaefer, L. M., Bosson, J. K., \& Thompson, J. K. (2015). Differential impact of upward and downward comparisons on diverse women's disordered eating behaviors and body image. International Journal of Eating Disorders, 49(5), 519-523. doi: 10.1002/eat.22470

Ridge, D. T. (2008) Recovery from Depression Using the Narrative Approach: A Guide for Doctors, Complementary Therapists, and Mental Health Professionals. London: Jessica Kingsley Publishers.

Rodgers, R. F., McLean, S. A., \& Paxton, S. J. (2015). Longitudinal relationships among internalization of the media ideal, peer social comparison, and body dissatisfaction: implications for the tripartite influence model. Developmental Psychology, 51(5), 706-713. doi: 10.1037/dev0000013

Roehrig, J. P. and McLean, C. P. (2010), A comparison of stigma toward eating disorders versus depression. International Journal of Eating Disorders, 43, 671-674. doi:10.1002/eat.20760

Saffran, K., Fitzsimmons-Craft, E. E., Kass, A. E., Wilfley, D. E., Taylor, C. B., \& Trockel, M. (2016). Facebook usage among those who have received treatment for an eating disorder in a group setting. International Journal of Eating Disorders, 49(8), 764-777. doi: 10.1002/eat.22567

Sanon, M. A., Evans-Agnew, R. A., \& Boutain, D. M. (2014). An exploration of social justice intent in photovoice research studies from 2008 to 2013. Nursing Inquiry, 21(3), 212-226. doi: 10.1111/nin.12064

Saunders, J. F., \& Eaton, A. A. (in press). Snaps, selfies, and shares: How social media use contributes to the sociocultural model of disordered eating among young women. Cyberpsychology, Behavior, and Social Networking,

Saunders, J. F., \& Eaton, A. A. (under review b). Social comparison in eating disorder recovery: using PhotoVoice to capture the sociocultural influences on women's recovery. Women \& Health. 
Saunders, J. F., Eaton, A. A., \& Fitzsimmons-Craft, E. E. (under review). Psychometric properties of the Body, Eating, and Exercise Comparison Orientation Measure $(\mathrm{BEECOM})$ in a sample of women in eating disorder recovery. Body Image.

Saunders, J. F. \& Frazier, L. D. (2017). Body dissatisfaction in early adolescence: The coactive roles of cognitive and sociocultural factors. Journal of Youth and Adolescence, 46(6), 1246-1261. doi:10.1007/s10964-016-0559-2.

Schaefer, L. M., Burke, N. L., Thompson, J. K., Dedrick, R. F., Heinberg, L. J., Calogero, R. M., . . Swami, V. (2015). Development and validation of the Sociocultural Attitudes Towards Appearance Questionnaire-4 (SATAQ-4). Psychological Assessment, 27(1), 54-67. doi:10.1037/a0037917

Schoenwald, S. K., McHugh, R. K., \& Barlow, D. H. (2012). The science of dissemination and implementation. Dissemination and implementation of evidence-based psychological interventions (pp. 16-42). Oxford: Oxford University Press.

Serpell, L., Treasure, J., Teasdale, J., and Sullivan, V. (1999). Anorexia nervosa: friend or foe? International Journal of Eating Disorders, 25, 177-186. doi: 10.1002/(SICI)1098- 108X(199903)25:23.0.CO;2-D

Shafran, R., Clark, D. M., Fairburn, C. G., Arntz, A., Barlow, D. H., Ehlers, A., Freeston, M.,...Wilson, G. T. (2009). Mind the gap: Improving the dissemination of CBT.

Behaviour Research and Therapy, 47, 902-909. doi:10.1016/j.brat.2009.07.003

Sigman, G. (1996). How has the care of eating disorder patients been altered and upset by payment and insurance issues? Let me count the ways. Journal of Adolescent Health, 19(5), 317-375. doi: 10.1016/S1054-139X(96)00218-2

Simpson, C. C., \& Mazzeo, S. E. (2017). Calorie counting and fitness tracking technology: associations with eating disorder symptomatology. Eating Behaviors, 26, 89-92. doi: 10.1016/j.eatbeh.2017.02.002

Spector, P. V. (2004). Social desirability bias. In M. S. Lewis-Beck, A. Bryman, \& T. Futing Liao (Eds.), The SAGE encyclopedia of social science research methods (pp. 1045-1046). Thousand Oaks, CA: Sage

Stice, E., Marti, C. N., \& Rohde, P. (2013). Prevalence, incidence, impairment, and course of the proposed DSM-5 eating disorder diagnoses in an 8-year prospective community study of young women. Journal of Abnormal Psychology, 122(2), 445. doi: 10.1037/a0030679 
Stice, E., Mazotti, L., Weibel, D., \& Agras, W. S. (2000). Dissonance prevention program decreases thin-ideal internalization, body dissatisfaction, dieting, negative affect, and bulimic symptoms: A preliminary experiment. International Journal of Eating Disorders, 27(2), 206-217. doi:10.1002/(SICI)1098108X(200003)27:2<206::AID-EAT9>3.0.CO;2-D

Strauss, A., \& Corbin, J. (1998). Basics of Qualitative Research: Techniques and Procedures for Developing Grounded Theory. Thousand Oaks, CA: Sage.

Tiggemann, M. (2011). Sociocultural perspectives on body image in T.F. Cash \& L. Smolak, (Eds.). Body image: A handbook of science, practice, and prevention (pp. 12-19). New York: Guilford Press.

Thompson, J. K., Heinberg, L. J., Altabe, M., Tantleff-Dunn, S. (1999) Exacting beauty: Theory, assessment, and treatment of body image disturbance. American Psychological Association: Washington, DC. doi:10.1037/10312-000

Thompson, J. K., Schaefer, L. M., \& Dedrick, R. F. (2018, e-pub ahead of print). On the measurement of thin-ideal internalization: Implications for interpretation of risk factors and treatment outcome in eating disorders research. International Journal of Eating Disorders, 1-5. doi: 10.1002/eat22839

Thompson, J. K., Stice, E. (2001). Thin-ideal internalization: Mounting evidence for a new risk factor for body-image disturbance and eating pathology. Current Directions in Psychological Science, 10, 181-183. doi:10.1111/1467-8721.00144.

Treasure, J., Stein, D., \& Maguire, S. Has the time come for a staging model to map the course of eating disorders from high risk to severe enduring illness? An examination of the evidence. Early Intervention in Psychiatry, 9(3), 173-184. doi: 10.1111/eip.12170

Tylka, T. L., Sabik, N. J. (2010). Integrating social comparison theory and self-esteem within objectification theory to predict women's disordered eating. Sex Roles, 63 (1-2), 18-31. doi: 10.1007/s11199-010-9785-3

Vetter, M.L., Herring, S.J., Sood, M., Shah, N.R., Kalet, A.L. (2008). What do resident physicians know about nutrition? An evaluation of attitudes, self-perceived proficiency and knowledge. Journal of the American College of Nutrition, 27(2), 287-298. doi: 10.1080/07315724.2008.10719702

Wade, T. D., Wilksch, S. M., Paxton, S. J., Byrne, S. M., \& Austin, S. B. (2017) Do universal media literacy programs have an effect on weight and shape concern by influencing media internalization? International Journal of Eating Disorders, 50, 731 738. doi:10.1002/eat.22689 
Wang, C., \& Burris, M. A. (1994). Empowerment through photo novella: Portraits of participation. Health Education \& Behavior, 21(2), 171-186.

doi: 10.1177/109019819402100204

Wang, C., \& Burris, M. A. (1997). Photovoice: Concept, methodology, and use for participatory needs assessment. Health Education \& Behavior, 24(3), 369-387. doi:10.1177/109019819702400309

Want, S. C. (2009). Meta-analytic moderators of experimental exposure to media portrayals of women on female appearance satisfaction: Social comparisons as automatic processes. Body Image, 6(4), 257-269.

doi: $10.1177 / 109019819702400309$

Whiteford, H. A., Degenhardt, L., Rehm, J., Baxter, A. J., Ferrari, A. J., Erskine, H. E., ... \& Burstein, R. (2013). Global burden of disease attributable to mental and substance use disorders: findings from the Global Burden of Disease Study 2010. The Lancet, 382(9904), 1575-1586. doi: 10.1016/S0140-6736(13)61611-6

Williams, P. M., Goode, J., Motsinger, C. D. (2008). Treating eating disorders in primary care. American Family Physician, 77(2), 187-195.

Winkler, L. A. D., Frølich, J. S., Gudex, C., Hørder, K., Bilenberg, N., \& Støving, R. K. (2017). Patient-and clinician-reported outcome in eating disorders. Psychiatry Research, 247, 230-235. doi: 10.1016/j.psychres.2016.11.047

Wissinger, E. (2015) This year's model: Fashion, media, and the making of glamour. New York: New York University Press.

Woolf, S. H., Zimmerman, E., Haley, A., Krist, A. H. (2016). Authentic engagement of patients and communities can transform research, practice, and policy. Health Affairs, 35(4), 590-594. doi:10.1377/hlthaff.2015.1512

Yager, J., Devlin, M. J., Halmi, K. A., Herzog, D. B., Mitchell, J. E., Powers, P., Zerbe, K. J. (2010). Practice guideline for the treatment of patients with eating disorders ( $3^{\text {rd }}$ edition).

Zerwas, S., Lund, B. C., Holle, A. V., Thornton, L. M., Berrettini, W. H., Brandt, H., ... Bulik, C. M. (2013). Factors Associated With Recovery from Anorexia Nervosa. Journal of Psychiatric Research, 47(7), 972-979.

doi: 10.1016/j.jpsychires.2013.02.011 
VITA

\section{JESSICA FAYE SAUNDERS}

2007

A.B., Psychology

Wellesley College

Wellesley, MA

2016

M.S., Psychology

Florida International University

Miami, FL

$2016-2018$

Doctoral Candidate

Psychology

Florida International University

Miami, FL

Instructor on Record

Florida International University

Miami, FL

\section{SELECT PUBLICATIONS \& PRESENTATIONS}

1. Saunders, J. F., Nichols-Lopez, K. A. \& Frazier, L. D. (2018) Psychometric Properties of the Intuitive Eating Scale-2 (IES-2) in a Culturally Diverse Hispanic American Sample. Eating Behaviors, 28, 1-7. doi:10.1016/j.eatbeh.2017.11.003

2. Saunders, J. F. \& Eaton, A. A. (2017, August). How does social media usage relate to the sociocultural model of disordered eating? Poster presented at the annual meeting of the American Psychological Association (APA, Division 35), Washington, D.C.

3. Saunders, J. F. (2017, March). Is comparison the thief of joy? Exploring the relationship between social media usage, social comparison, and disordered eating. Invited research presentation at Emmanuel College, Boston, MA.

4. Saunders, J. F. \& Frazier, L. D. (2017). Body Dissatisfaction in Early Adolescence: The Coactive Roles of Cognitive and Sociocultural Factors. Journal of Youth and Adolescence, 46(6), 1246-1261. doi:10.1007/s10964-016-0559-2.

5. Saunders, J. F., Frazier, L. D., \& Nichols-Lopez, K.A. (2016). Self-Esteem, Diet SelfEfficacy, Body Mass Index, and Eating Disorders: Modeling Effects in an Ethnically Diverse Sample. Journal of Eating and Weight Disorders- Studies on Anorexia, Bulimia, and Obesity, 21(3), 459-468. doi: 10.1007/s40519-015-0244-6 